\title{
No. 14
}

FEBRERO DE 2017

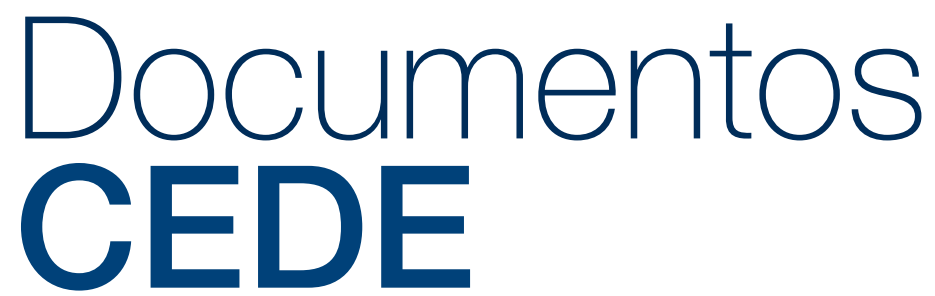

ISSN 1657-7191 Edición electrónica.

Pension Incentives and Formal-Sector Labor Supply: Evidence from Colombia

Oscar Becerra 


\section{CEDE}

D1)

Facultad de Economía

Serie Documentos Cede, 2017-14

ISSN 1657-7191 Edición electrónica.

Febrero de 2017

(C) 2017, Universidad de los Andes, Facultad de Economía, CEDE. Calle 19A No. 1 - 37 Este, Bloque W.

Bogotá, D. C., Colombia Teléfonos: 3394949- 3394999, extensiones 2400, 2049, 2467

infocede@uniandes.edu.co

http://economia.uniandes.edu.co

Impreso en Colombia - Printed in Colombia

La serie de Documentos de Trabajo CEDE se circula con propósitos de discusión y divulgación. Los artículos no han sido evaluados por pares ni sujetos a ningún tipo de evaluación formal por parte del equipo de trabajo del CEDE.

El contenido de la presente publicación se encuentra protegido por las normas internacionales y nacionales vigentes sobre propiedad intelectual, por tanto su utilización, reproducción, comunicación pública, transformación, distribución, alquiler, préstamo público e importación, total o parcial, en todo o en parte, en formato impreso, digital o en cualquier formato conocido o por conocer, se encuentran prohibidos, y sólo serán lícitos en la medida en que se cuente con la autorización previa y expresa por escrito del autor o titular. Las limitaciones y excepciones al Derecho de Autor, sólo serán aplicables en la medida en que se den dentro de los denominados Usos Honrados (Fair use), estén previa y expresamente establecidas, no causen un grave e injustificado perjuicio a los intereses legítimos del autor o titular, y no atenten contra la normal explotación de la obra.

Universidad de los Andes | Vigilada Mineducación

Reconocimiento como Universidad: Decreto 1297 del 30 de mayo de 1964. Reconocimiento personería jurídica: Resolución 28 del 23 de febrero de 1949 Minjusticia. 


\title{
Pension Incentives and Formal-Sector Labor Supply: Evidence from Colombia
}

\author{
Oscar Becerra*t
}

\begin{abstract}
This paper describes how future pension benefits a ffect 1 abor s upply in e conomies that have an informal sector. From the perspective of the worker, a formal-sector job offers longrun gains, as it increases his likelihood of gaining pension benefits in the $\mathrm{f}$ uture. If workers take those gains into account when they search for formal-sector jobs, the pension system affects formal-sector labor supply. I estimate the causal link between pension incentives and formal-sector labor supply using a cohort-based reform undertaken in Colombia. I demonstrate that a change in future pension benefits generates a large shift between the formal-sector and informal-sector labor supply, and that this change does not affect labor force participation. The average effect of pension incentives on formal-sector labor supply is heterogeneous, and is consistent with the predictions of a theoretical model combining a pension system and informal job opportunities. The effect is concentrated among workers for whom the minimum qualifying conditions are binding, and among workers with higher expected pension wealth. The results presented here suggest that pension reforms have the potential to create large efficiency costs, an effect that should be taken into account when designing pension programs.
\end{abstract}

Keywords: Labor supply, informal economy, pension benefits.

JEL Codes: J22, J26, J32, J46, H21

*Universidad de los Andes obecerra@ uniandes.edu.co.

${ }^{\dagger}$ I would like to thank Joshua Gottlieb, Thomas Lemieux, Florian Hoffman, Kevin Milligan, David Green, participants at the CEA conference, workshop participants at UBC and the UBC Public Finance Reading Group for helpful comments and valuable discussion. I also thank Carlos Prada and Luz Angela Malagón from the Colombian Statistics office (DANE), and Mauricio Olivera and Adriana Hernandez from Colpensiones for facilitating access to the Census, PILA and Colpensiones datasets. This work represents the view of the author and does not necessarily reflect those of DANE or Colpensiones. 


\title{
Incentivos pensionales y oferta laboral en el sector formal: Evidencia de Colombia
}

\author{
Oscar Becerra ${ }^{* \dagger}$
}

\begin{abstract}
Resumen
Este paper describe cómo beneficios pensionales futuros afectan la oferta laboral en una economía con un sector informal. Desde el punto de vista de un trabajador, un empleo en el sector formal ofrece ganancias en el largo plazo, ya que aumenta la probabilidad de que el trabajador obtenga una pensión. Si los trabajadores tienen en cuenta estos beneficios cuando están buscando empleo, el sistema pensional afecta la oferta laboral del sector formal. Usando una reforma basada en fecha de nacimiento ocurrida en Colombia, el paper estima la relación causal entre los beneficios pensionales y la oferta laboral en el sector formal. Se muestra que un cambio en los beneficios pensionales futuros generan cambios en la oferta de empleo formal e informal, pero este cambio no afecta la participación en la fuerza laboral. El efecto promedio de los beneficios pensionales es heterogeneo, lo cual es consistente con las predicciones de un modelo que combina un sistema pensional y oportunidades de trabajo informal. El efecto está concentrado en trabajadores para los cuales las condiciones mínimas para alcanzar una pensión son efectivas, y en trabajadores con una mayor riqueza pensional. Los resultados presentados sugieren que reformas pensionales tienen el potencial de generar costos de eficiencia significativos, un efecto que debe ser tenido en cuenta en el diseño de progamas pensionales.
\end{abstract}

Palabras clave: Oferta laboral, economía informal, beneficios pensionales.

Códigos JEL: J22, J26, J32, J46, H21

*Universidad de los Andes obecerra@uniandes.edu.co.

${ }^{\dagger}$ Agradezco a Joshua Gottlieb, Thomas Lemieux, Florian Hoffman, Kevin Milligan, David Green, a los asistentes a la conferencia de la CEA y los seminarios de UBC por todos sus valiosos comentarios. También agradezco a Carlos Prada y Luz Angela Malagón del Departamento Nacional de Estadística (DANE), y Mauricio Olivera y Adriana Hernandez de Colpensiones por facilitar el acceso a las bases de datos del Censo 2005, PILA y afiliados a Colpensiones. Este trabajo representa mis puntos de vista y no necesariamente refleja los puntos de vista del DANE ni Colpensiones. 


\section{Introduction}

How does the prospect of future pension benefits determine workers' choices in developing economies? Workers in these economies are able to respond to public policies by changing their search strategies for finding work between the formal and informal sectors. If workers respond to the prospect of pension benefits by changing their search for formal-sector jobs, then the pension system affects formal-sector labor supply.

Workers' behavioral responses along the formal-informal margin are an important consideration for the design of retirement policies in Latin American countries. In Latin America, approximately 50 percent of workers do not contribute to the pension system. Since most of these workers have a low income, the lack of pension contributions exacerbates income inequality after retirement (Frölich, Kaplan, Pagés, Rigolini, and Robalino, 2014). Latin American policymakers have implemented major pension reforms in response to concerns about low coverage and high inequality in benefits. These reforms have included new types of funding, changes in qualifying conditions for receiving a pension, and the introduction of pension assistance programs. ${ }^{1}$ Yet these reforms have a potential offsetting cost. They may reduce the workers' expected gains from retirement contributions, thereby reducing the incentive to search for formal-sector jobs.

Despite the importance of workers' behavioral response to retirement policies, the empirical evidence establishing a causal link between pension incentives and formal-sector labor supply is scarce. The main empirical challenge is that the observable determinants of a worker's expected pension benefits are likely correlated with unobservable determinants of the worker's current labor choices. In absence of non-linear patterns in the pension benefit formulas, the variation in determinants of future expected benefits does not identify the causal link between pension-related incentives and formal-sector labor supply (Liebman, Luttmer, and Seif, 2009).

In this paper, I estimate the causal link between pension-related incentives and formal sector labor supply. I overcome the identification problem using quasi experimental variation from a cohort-based reform to the Colombian pension system. In 1993, the Colombian government increased the pension contribution rate and changed the minimum qualifying conditions for receiving a pension in the defined-benefit system. However, the reform did not change the qualifying conditions for eligible men born before April 1954 and eligible women born before April 1959. Compared with younger workers, eligible workers could retire contributing for fewer years (20 years instead of up to 25), and at an earlier age (55 years for women and 60 years for men, instead of 57 and 62). In this way, the reform permanently changed the long-run gains from a formal-sector

\footnotetext{
${ }^{1}$ Ten countries in the region implemented major reforms to their pension systems: Chile (1981 and 2008), Peru (1993), Colombia (1994), Argentina (1994, 2008), Uruguay (1996), Mexico (1997), Bolivia (1997), El Salvador (1998), Costa Rica (2000), Nicaragua (2000), and Dominican Republic (2003). A detailed list and discussion of other non-contributory pension programs is in Bosch, Melguizo, and Pagés (2013).
} 
job depending on the worker's birth date.

The difference in qualifying conditions by date of birth provides a source of exogenous variation to estimate the causal link between pension-related incentives and formal-sector labor supply. To estimate this effect, I implement a two-stage procedure. First, I use a regression discontinuity design (RD) on two new confidential datasets from 2005 and 2011. I compute the difference between formal-sector outcomes for workers born just before and just after the eligibility cutoffs. If there is no other economic or institutional factor to explain a discontinuous change in formal-sector labor supply at the cutoff, the difference is an estimate of the causal link between pension-related incentives and formal-sector labor supply. Second, I use additional assumptions to recover the elasticity of the formal-sector labor supply with respect to the net-of-tax share, a measure of the efficiency costs of pension taxes (Feldstein and Liebman, 2002).

To understand the impact of the change in qualifying conditions on formal-sector labor supply, I develop a model that characterizes workers' decisions about retirement and job search in the formal and informal sectors. The model builds on the framework proposed by Chetty (2006) for unemployment insurance and adapted by Gerard and Gonzaga (2014) to include an informal sector. I modify the model to incorporate a defined-benefit pension system, where the worker is entitled to a pension after reaching a minimum retirement age and a minimum number of years of contributions (the vesting period). In the model, workers search for formal-sector jobs because these jobs increase the likelihood of getting pension benefits in the future. Within an age group, the long-run gains from working in the formal-sector are a nonlinear function of the years of contribution. The higher gains concentrate among workers who are just below the vesting period, since they are the ones more likely to see the vesting period as binding.

The comparative statics of the model show that the effect of an increase in the minimum qualifying conditions on labor supply is heterogeneous, and that even its sign is ambiguous. The direction of the response depends on the worker's previous contributions relative to the new vesting period. On the one hand, workers who are a long way from satisfying the new vesting requirement reduce their search effort for formal-sector jobs, given their low likelihood of ever vesting. On the other hand, workers who are close to satisfying the new vesting requirement increase their search effort for formal-sector jobs to secure their pension benefits. The magnitude of the effect depends on the worker's age and opportunities to find a formal-sector job.

I present four main empirical findings. First, there is a sizable and significant response in formal-sector labor supply to changes in pension incentives. The effect is concentrated among men. For men, the average effect of harder qualifying conditions on salaried-formal labor supply is negative 12 percent in 2005, while it is positive 7 percent in 2011. The change is consistent with the insights provided by the model. By 2005, many workers born before April 1954 had not reached the minimum 20 years of contribution for a pension, giving them more incentives to 
work in the formal-sector than workers born after April 1954, who have to contribute to the system a minimum of 25 years. By 2011 many workers born before April 1954 had already met the required 20 years of contribution, thereby losing their incentive to contribute. In addition, I find little evidence suggesting that the changes in the formal-sector labor supply is offset by changes in wages.

Second, the change in formal employment is related to a shift from self-employment to salariedformal employment, with no response along the extensive margin. The estimated effect of harder qualifying conditions on self-employment (which is mostly informal) is positive and of similar magnitude to the negative effect on salaried-formal employment. The estimated effect on labor force participation is not significant. These results are similar to those of Almeida and Carneiro (2012), who found that higher mandated benefits with no wage adjustment generate an incentive for self-employed workers to switch to salaried-formal jobs.

Third, the response of formal-sector labor supply to pension incentives is heterogeneous, and depends on the worker's labor market opportunities. The effect is concentrated among workers for whom the minimum qualifying conditions are binding. I analyze the response for groups with different propensities to work in the formal sector (e.g., education and region). In the analysis by educational attainment, I find that workers with primary and post-secondary education are less responsive to pension incentives than workers with secondary education. This result is consistent with the model predictions; workers for whom the minimum qualifying conditions are not binding are less sensitive to changes in pension incentives. Intuitively speaking, increasing the likelihood of securing future pension benefits is not a relevant factor for workers with no prospect of getting a pension, or workers who know with certainty they will get a pension. I obtain consistent results for other subsamples, such as those based on regional variation and marital status.

Fourth, I estimate an elasticity of the formal-sector labor supply with respect to the net-oftax share of 1.7. Using variation by region and education, I regress the change in formal-sector employment at the discontinuity on the change in the predicted net-of-tax share for workers at the discontinuity. Consistent with the predictions of the model, workers with higher pension incentives along the formal-informal margin also exhibit higher responses in formal-sector labor supply. The estimate is likely a lower bound of the actual elasticity, suggesting large behavioral responses.

The paper is organized as follows: Section 2 describes the labor market institutions and the Colombian pension system. Section 3 presents the conceptual framework that provides insights about the expected sign and sources of heterogeneity in the results. Section 4 discusses the identification strategy and the data sources. Section 5 reports the estimation results, and Section 6 concludes. 


\section{Institutional background}

\subsection{Labor market institutions}

The Colombian government mandates that employers provide benefits to their employees, and that self-employed workers contribute to the pension and contributory health care systems. Workers covered by mandated benefits are considered formal-sector workers.

Formal-sector jobs generate two types of gains for workers. First, formal-sector workers have access to mandated benefits. For salaried workers, formal-sector jobs provide the following: insurance from the pension and contributory health care systems, paid vacations (two weeks per year), severance payments (an additional monthly wage per year of tenure), a maximum number of working hours (48 per week), maternity leave (14 weeks), a 13th month of pay each year, access to subsidies for children's education, and compliance with the minimum wage. For self-employed workers, the gain from paying their contributions is limited to the insurance provided by the pension and the contributory health care systems. ${ }^{2}$

Second, formal-sector workers earn higher wages. As La Porta and Shleifer (2014) show, formal-sector firms tend to pay higher wages than informal-sector firms, and formal self-employed workers tend to have more education. Using data from the household surveys (described in Section 4.1), Table 1 presents the average wage and distribution of urban workers aged 20 to 65 who work at least 30 hours per week. In the table, I define a formal-sector worker as a worker making a contribution to the pension system and covered by the contributory health care system. ${ }^{3}$ The average formal-to-informal wage gap is 75 percent for salaried workers and 100 percent for selfemployed workers. The wage gap is positive regardless of the worker's level of education and type of employment. Nonetheless, as Figure 1 shows, the wage for a large fraction of informal-sector workers is above the minimum wage.

Despite the gains available from working in the formal sector, other supply and demand factors may prevent workers from working in this sector. On the labor supply side, workers may find it optimal to work in the informal sector (Maloney, 2004). Studies show that low valuation of mandated benefits, social programs that substitute the mandated benefits, and preferences for independent work reduce the incentives to search for formal-sector jobs (Levy, 2008; Perry et al., 2007). On the labor demand side, firms may find it optimal to operate informally in response to high regulation costs and weak enforcement, thereby reducing workers' chances of finding a

\footnotetext{
${ }^{2}$ The minimum contributions for the pension and contributory health care systems are 16 and 12 percent of the minimum wage.

${ }^{3}$ The coverage of pension and contributory health care systems is a widely-used measure of formal employment (Perry, Maloney, Arias, Fajnzylber, Mason, and Saavedra-Chanduvi, 2007). Because workers are not subject to penalties for being without coverage, it is unlikely that they would misreport their coverage status. Moreover, the formal employment indicators are consistent with aggregate statistics obtained from administrative data.
} 
formal-sector job. The effect of labor market regulation is evident in Figure 1, as a large fraction of formal-sector workers earn the minimum wage.

\subsection{The Colombian pension system}

In 1993, the Colombian government introduced the General Pension System (GPS), a new system intended to increase coverage and equality in retirement benefits while improving the financial viability of the system. The GPS integrates two pension systems: a new system to cover all new entrants, men born after March 1954, and women born after March 1959; and a transition system to cover all other workers.

For young workers and new entrants, the GPS allows workers to choose between two pension systems. All public and private sector workers must contribute to one system, and their choice determines their pension eligibility and benefits. ${ }^{4}$ The first system, the social insurance system, allows workers to contribute to a defined-benefit pension plan managed by Colpensiones (the public pension fund). In the defined-benefit plan, the pension benefits are the maximum between a fraction of the worker's wage and the minimum wage, while eligibility is based on the worker's age and years of contribution. The second system, the individual account system, allows workers to contribute to a defined-contribution plan managed by private pension funds. In the definedcontribution plan, the pension fund invests the worker's contributions in the capital market, and the principal and returns constitute the worker's savings for retirement. The worker's benefits and eligibility are based on the accrued capital. The defined-contribution plan also includes a guaranteed minimum pension of a monthly minimum wage. Eligibility for the guaranteed minimum pension is based on the worker's age and years of contribution.

For all other workers, the GPS is the transition system where workers contribute to a definedbenefit plan managed by Colpensiones. Unlike the social insurance system, the transition system retains the pre-reform eligibility and benefits for eligible workers. The eligibility criteria were based on age and contributions at the time the reform took effect (April 1, 1994). Originally, three groups of employees were eligible for the transition system: men born before April 1954 who had contributed before April 1994, women born before April 1959 who had contributed before April 1994, and younger workers who had contributed to the system for at least 750 weeks (just over 14 years). A 2005 reform required eligible workers to have contributed more than 750 weeks by July 2005 and meet the qualifying conditions by $2014 .^{5}$

\footnotetext{
${ }^{4}$ Workers can switch systems every five years, up to the last ten years before the minimum retirement age (62 for men and 57 for women).

${ }^{5}$ In the rest of the paper, I focus on the eligibility criteria based on the date of birth of the worker. The criterion based on 750 weeks by 1993 has a limited effect on younger workers, given that the requirement implies that men younger than 40 and women younger than 35 would have worked by at least 14 years in the formal sector. Moreover, after the 2005 reform, men born after 1954 and women born after 1959 became ineligible for the transition system,
} 
Table 2 and Figure 2 summarize the main characteristics of the GPS. Workers in the three systems face the same contribution rate (16 percent) but different minimum qualifying conditions. Compared with younger workers and new entrants, an eligible worker could retire having contributed for fewer years (20 years instead of up to 25) and at an earlier age (55 years for women and 60 years for men instead of 57 and 62). Although the transition system has a higher replacement rate than the social insurance system, the minimum pension guarantee implies that low wage workers face the same effective replacement rate in both systems (Figure 2). This is a relevant feature of the system given that 90 percent of workers in the GPS report earnings between one and two times the minimum wage.

Relevance of the minimum qualifying conditions. The importance of differences in the minimum qualifying conditions for a pension depends on whether the workers take these conditions into account when making their retirement decisions. Figure 3 shows that most workers claim their pension benefits as soon they meet the requirements. Based on statistics from Colpensiones, Figure 3 displays the distribution by age and weeks of contribution for non-retired men and women who contributed to Colpensiones up to December 2013. I focus on workers around the minimum retirement age, 60 years for men and 55 years for women. The distribution exhibits a clear discontinuity at the minimum retirement age when the number of weeks is above 1,000 (the minimum for the transition system) and the discontinuity widens as the number of weeks increases.

Interactions with other programs. The introduction of the General Pension System generated cohort differences in the minimum qualifying conditions and pension benefits received by workers. However, the differences in the conditions may have a limited effect on the workers' behavior if there were other cohort-based assistance programs targeted to the same population.

In recent years, Colombia has expanded several non-contributory social assistance programs. Three of the most significant programs are the non-contributory health care system, conditional cash transfers for families with children aged 0 to 17 , and a subsidy of approximately 20 percent of the minimum wage for old-age population. The eligibility for these programs is based on a poverty score index computed by the Colombian government, and the programs' eligibility threshold changes by program. An important feature of the poverty score index is that it does not depend on whether the person has a formal-sector job, or whether the person is eligible for the transition system. Consequently, other assistance programs do not offset the cohort differences caused by eligibility for the transition system.

even though they could have met the original eligibility criteria. 


\section{Pension incentives and formal-sector labor supply}

To understand the incentives that workers consider when making their labor supply decisions, I present a model of workers' decisions with respect to retirement and formal-sector participation. In this model, a representative worker chooses between retiring and searching for a job, given a defined-benefit pension plan and a labor market with an informal sector.

The representative worker lives for $T-a_{0}+1$ periods, indexed by $a=a_{0}, \ldots, T$. Each period, the worker chooses whether to retire and leave the labor market permanently. If he retires and is eligible for retirement benefits, he receives a fraction $b$ of the wage in the formal sector $w^{f}$ along with other benefits valued $\theta^{r}$ (e.g., health care). If he retires and is not eligible for retirement benefits, he gets zero income. Thus, the retiree's earnings at age $a$ are $e_{a}\left(\tau_{a-1}\right) b w^{f}$. The variable $e_{a}\left(\tau_{a-1}\right)$ is an indicator of the worker's pension eligibility, where $\tau_{a-1}$ stands for the number of periods the worker has worked in the formal sector. To be entitled to retirement benefits, the worker is required to work for at least $\tau^{*}$ periods in the formal sector and be at least $R$ periods old, and thus $e_{a}\left(\tau_{a-1}\right)=1\left\{\tau_{a-1} \geq \tau^{*}\right\} \cdot 1\{a \geq R\}$.

If the worker does not retire, he draws a random shock of searching for a formal-sector job $\psi_{a} \in \mathbb{R}$, which follows an i.i.d distribution with cumulative distribution $G(\cdot)$. $\psi_{a}$ is measured in utility units and it is used as a catch-all variable summarizing the relative cost of searching and workers' preferences for formal-sector jobs. After drawing $\psi_{a}$, the worker decides between working in the formal sector and working in the informal sector. If he chooses to work in the formal sector, he will receive a wage $w^{f}$ along with mandated benefits (valued $\theta^{f}$ ), will face the utility shock $\psi_{a}$, and will be liable to pay the pension tax rate $t^{\text {nom }}$. Additionally, his cumulative number of periods with a contribution to the pension system will increase by one period ( $\operatorname{so} \tau_{a}=\tau_{a-1}+h_{a}$, where $h_{a}$ is an indicator of whether the worker searches for a formal-sector job). If he chooses to work in the informal sector, he will receive a wage $w^{i}$ (I assume that $w^{i} \leq w^{f}\left(1-t^{n o m}\right)$ and $\left.\theta^{r} \geq \theta^{f}\right)$. For simplicity, I assume that the worker loses his job at the end of the period, and that he cannot save. It is possible to show that the model implications are robust to more general assumptions.

Since the worker does not save, so his consumption per period is equal to his income. Let $r_{a}$ denote an indicator of whether the worker retires at the beginning of period $a$. Given $\tau_{a-1}$, the worker's problem at the beginning of period $a$ is

$$
v_{a}\left(\tau_{a-1}\right)=\max _{r_{a} \in\{0,1\}}\left\{v_{a}^{w}\left(\tau_{a-1}\right), v_{a}^{r}\left(\tau_{a-1}\right)\right\}
$$


where

$$
\begin{aligned}
& v_{a}^{w}\left(\tau_{a-1}\right)=\mathbb{E} \max _{h_{a} \in\{0,1\}}\left\{u\left(w^{i}\right)+\beta v_{a+1}\left(\tau_{a-1}\right),\right. \\
&\left.u\left(w^{f}\left(1-t^{n o m}\right)\right)+\theta^{f}-\psi_{a}+\beta v_{a+1}\left(\tau_{a-1}+1\right)\right\} \\
& v_{a}^{r}\left(\tau_{a-1}\right)=u\left(e_{a}\left(\tau_{a-1}\right) b w^{f}\right)+e_{a}\left(\tau_{a-1}\right) \theta^{r}+\beta v_{a+1}^{r}\left(\tau_{a-1}\right)
\end{aligned}
$$

and $\tau_{a_{0}-1}=0$. In the definitions above, $u(c)$ is the worker's utility over current consumption, which I assume to be continuous, strictly increasing, convex, and state-independent; $0<\beta<1$ is the discount factor, and $v_{T+1}^{w}\left(\tau_{T}\right)=v_{T+1}^{r}\left(\tau_{T}\right)=0$.

The model encompasses the two common views in the literature about the incentives for workers to work in the informal sector (Gerard and Gonzaga, 2014). First, workers may choose to work in the informal sector because the perceived gains from formal-sector jobs are low. In the model, low gains from searching are represented by a low formal-to-informal wage gap and a low valuation of the mandated benefits provided by a formal-sector job (i.e., low $\theta^{f}$ and $\beta$ ). Second, workers may choose to work in the informal sector because finding a formal-sector job is difficult due to labor market rigidities and other structural characteristics (e.g., preferences for independent work). In the model, less favorable labor market opportunities are represented by a distribution of search costs with a heavier right tail. When $G(\psi)$ has a heavy right tail, it is likely that the worker draws a large value of $\psi$, high enough to offset the gains from working in the formal sector. It is common to have these two forces interact and reinforce each other. For example, workers with narrower wage gaps may also face higher search costs, further reducing the incentive to work in the formal sector.

\subsection{Retirement and formal-sector participation decisions}

The labor supply plan that solves the worker's problem can be obtained by backward induction. Given the value function, the worker's labor supply and retirement decisions can be obtained in a two-stage procedure. In the first stage, the worker finds the optimal plan for searching for a formal-sector job and the value function from working. In the second stage, the worker compares the value function from working with the value function from retiring, and determines the optimal retirement decision policy.

In the first stage, given a realization of the search cost $\psi_{a}$, the worker searches for a job in the formal sector as long as the gains from the search are greater than the costs. Thus, the worker searches for a formal-sector job (sets $h_{a}=1$ ) if

$$
\bar{u}_{a}\left(\tau_{a-1}\right)=\tilde{u}+\beta \Delta v_{a+1}\left(\tau_{a-1}+1\right) \geq \psi_{a}
$$


where $\tilde{u}$ and $\Delta v_{a+1}\left(\tau_{a-1}+1\right)$ are defined as

$$
\begin{aligned}
\tilde{u} & =u\left(w^{f}\left(1-t^{n o m}\right)\right)+\theta^{f}-u\left(w^{i}\right) \\
\Delta v_{a+1}\left(\tau_{a-1}+1\right) & =v_{a+1}\left(\tau_{a-1}+1\right)-v_{a+1}\left(\tau_{a-1}\right) .
\end{aligned}
$$

In inequality (2), $\bar{u}_{a}\left(\tau_{a-1}\right)$ summarizes the gains from working in a formal-sector job. The first term represents the short-run gains, that is, the utility gains determined by the differences in wages in both sectors along with the mandated benefits. The second term represents the long-run gains, that is, the gain that one additional period of working in the formal sector has on the likelihood that the worker will receive pension benefits in the future.

From inequality (2), the ex ante probability that a worker works in the formal sector is

$$
P\left(h_{a}=1 \mid \tau_{a-1}\right)=G\left(\bar{u}_{a}\left(\tau_{a-1}\right)\right)
$$

and the value function from working is

$$
\begin{aligned}
v_{a}^{w}\left(\tau_{a-1}\right)= & u\left(w^{i}\right)+v_{a+1}\left(\tau_{a-1}\right) \\
& +G\left(\bar{u}_{a}\left(\tau_{a-1}\right)\right) \mathbb{E}\left(\bar{u}_{a}\left(\tau_{a-1}\right)-\psi_{a} \mid \psi_{a} \leq \bar{u}_{a}\left(\tau_{a-1}\right)\right) .
\end{aligned}
$$

In the second stage, the worker retires if the value function from retiring is greater than the value function from working. Thus, the worker retires ( $\operatorname{sets} r_{a}=1$ ) if

$$
v_{a}^{r}\left(\tau_{a-1}\right) \geq v_{a}^{w}\left(\tau_{a-1}\right)
$$

\subsection{Model implications}

The model provides four useful predictions that contribute to understand the empirical results of the paper. The first three predictions are discussed in detail in the Appendix A.

The first prediction of the model is that, when the replacement rate equals one, the worker retires as soon as he meets the qualifying conditions. The retiree receives the wage in the formal sector as pension and does not have to pay the search cost. Since $b=1$ is the effective rate faced by Colombian low-wage workers, the result is consistent with the patterns reported in Section 2.2, where workers retire as soon as they meet the minimum requirements of age and years of contribution. ${ }^{6}$ Values of $b$ lower than one may delay the retirement decision, depending on the value function conditional on working.

\footnotetext{
${ }^{6}$ An alternative explanation is that the worker is myopic or information constrained. If so, he may take the requirement conditions as target values regardless of the incentive to delay his retirement. I also develop a version of the model in which the minimum retirement age is exogenous, and the predictions hold.
} 
The second prediction of the model is that the long-run gains from a formal-sector job are heterogeneous and depend on the worker's employment history $\left(\tau_{a-1}\right)$. Equations (2) and (3) imply that the worker's search for formal-sector jobs depends on the long-run gains from working in the formal sector. However, not all workers have the same long-run gains. Workers who cannot accumulate enough years to meet the vesting requirement will not receive pension benefits; therefore their long-run gains from a formal-sector job are zero $\left(\Delta v_{a+1}\left(\tau_{a-1}+1\right)=0\right)$. Similarly, workers who already met the vesting requirement do not have long-run gains from working an extra period in the formal sector. For the remaining workers, the long-run gains from working in the formal sector are positive. Because the probability of working in the formal sector is an increasing function of the long-run gains from a formal-sector job, the result implies that workers with positive long-run gains search more actively for formal-sector jobs. Nonetheless, some workers with no long-run gains continue to work in the formal sector, but their decision is motivated by short-run gains only.

The third prediction of the model is that a change in the minimum retirement age $R$ or the vesting period $\tau^{*}$ affects formal-sector labor supply. The effect of an increase in $R$ on formalsector labor supply is negative, since it reduces the long-run gains from working in the formal sector. In contrast, the effect of an increase in $\tau^{*}$ on formal-sector labor supply is ambiguous. The increase in $\tau^{*}$ shifts the long-run gains from working in the formal sector to the right, generating two opposite effects depending on the worker's employment history. On the one hand, workers who are close to meeting the new vesting requirement increase their search efforts to reach the new threshold. On the other hand, workers with a few existing years of contribution reduce their search efforts because it is unlikely that they will meet the new requirement.

Finally, the fourth prediction of the model is that the magnitude of the response to changes in the qualifying conditions for retirement depends on the worker's labor market opportunities. The response is smaller in labor markets with low formality rates (a low value of $\tilde{u}$ and a search cost distribution with a heavy right tail), and labor markets with high formality rates (a high value of $\tilde{u}$ and a search cost distribution with a light right tail). When $P\left(h_{a}=1 \mid \tau_{a-1}\right) \rightarrow 0$, workers cannot reach the vesting requirement and the long-run gains from searching are zero. When $P\left(h_{a}=1 \mid \tau_{a-1}\right) \rightarrow 1$, workers always reach the vesting requirement and the long-run gains from searching for formal-sector jobs are zero. The effect of changes in the qualifying conditions is concentrated among workers who struggle to meet the vesting requirement but for whom reaching this threshold is still possible.

Figure 4 shows the expected value function $\left(v_{a+1}\left(\tau_{a}\right)\right.$, top) and the probability of searching for a formal-sector job $\left(G\left(\bar{u}_{a}\left(\tau_{a-1}\right)\right)\right.$, bottom) by years of contribution for two simulated cohorts aged $a=50$. Both cohorts face the same labor market opportunities, but different defined-benefit pension plans. One plan sets a minimum retirement age of $R=60$ years, a vesting period of $\tau^{*}=$ 
20 years, and a replacement rate of $b=1$. The other plan sets $R=62, \tau^{*}=25$ and $b=1$. $^{7}$ Since $b=1$ in both plans, workers facing both schemes retire as soon as they meet the requirements. For both cohorts, the long-run gains from working one more period in the formal sector are higher in years just below the vesting period, as working in the formal sector increases more the likelihood of securing pension benefits. As a result, the probability of working in the formal sector is higher in years just below the vesting period. An increase of the minimum qualifying conditions shifts the expected value function to the right (workers have to work more time to reach the vesting period) and reduces its level (workers receive the pension benefits for less time).

The probability of working in a formal-sector job given the two pension plans is presented in the bottom panel of Figure 4. The figure shows that an increase in the minimum qualifying conditions has a heterogeneous effect on the formal-sector labor supply, depending on the years of formalsector experience. Workers with a few years of experience are not sensitive to different qualifying conditions, as they are too far from reaching the vesting requirements. Similarly, workers with many years of formal-sector experience are not sensitive to different qualifying conditions, as they already secured their pension benefits. For the rest of workers, the increase of the minimum qualifying conditions has two types of effects on formal-sector employment. On the one hand, harder qualifying conditions discourage workers with a few periods of formal-sector experience, given the difficulty in reaching the new vesting requirement. On the other hand, more difficult qualifying conditions encourage workers approaching the new vesting requirement to search for formal-sector jobs, given that they are required to contribute additional years to reach the new vesting period. The sign of the overall effect of changes in minimum qualifying conditions on formal-sector labor supply is ambiguous and depends on the distribution of the workers' formalsector experience.

\subsection{General equilibrium}

The model shows that future pension benefits create incentives for workers to work in the formal sector. In general equilibrium, though, changes in the long-run gains from working in the formal sector should be offset by changes in wages. Because future pension benefits are attractive to workers, workers would be willing to give up part of their wage in order to get the long-run gains from a formal-sector job (Summers, 1989).

The previous observation implies that, in equilibrium, the wage gap should exhibit an inverse pattern to that observed in Figure 4. Changes in qualifying conditions would be reflected in wages, leaving formal employment unchanged. However, the result requires that the extra benefits can

\footnotetext{
${ }^{7}$ In addition, I assume that workers' work from $a_{0}=20$ up to $T=75$ years and their utility is linear. I also assume that $w^{f}\left(1-t^{n o m}\right)=1.2, w^{i}=1, \theta^{r}=\theta^{f}=0, \psi \stackrel{i . i . d}{\sim} \mathcal{U}(0,0.5)$, and $\beta=\frac{1}{1.05}$.
} 
be passed on to workers by way of lower wages, which are determined by the wage-setting process (Saez, Matsaganis, and Tsakloglou, 2012). Institutional factors such as minimum wage laws, search based on posted earnings, unobservable employment history, and pay fairness norms may prevent firms from setting differential wages among workers. If firms are not able to set a different wage scale for workers who do similar work, the response of the formal-sector labor supply changes the wage gap for all workers. As a result, the comparative statics of changes in the minimum retirement age and the vesting period exhibit similar patterns to the presented in Figure 4.

\section{Data and empirical approach}

\subsection{Data}

To measure the effects of changes in qualifying conditions on formal-sector labor supply, I combine two new sources of confidential data. The first source is the microdata from the long-form questionnaire of the Colombian Census of 2005. This is a cross-sectional dataset including information about labor market outcomes, pension and health care coverage, and demographic and household characteristics. The second source is the PILA dataset of 2011, an administrative dataset that collects information on all workers and earnings in the formal sector.

These two datasets have limitations but are highly complementary: I am able to analyze factors with the Census dataset that I am not able to analyze with the PILA dataset, and vice versa. In particular, the Census dataset does not include information about workers' earnings, while the PILA dataset does not include information about informal employment or demographic characteristics. Moreover, using both datasets, I am able to study the response of the formal-sector labor supply to changes in the pension incentives as the workers age.

Neither the Census nor PILA datasets includes the worker's employment history. I complement the information from the Census and PILA datasets with the distribution of years of contributions from the Colombian household surveys.

\subsubsection{Colombian Census (2005)}

The long-form questionnaire of the Colombian Census for 2005 collates information from 2 million households and 9.7 million people, approximately 20 percent of Colombian households. The dataset includes date of birth (in months), demographic information, type of employment, contributions to the pension system, and health care system coverage. The information about date of birth is reliable since the interviews were carried out in person and the interviewer was able to verify the date of birth from the respondent's identification card. In the absence of an identification card, the date of birth was either provided by the respondent or inferred on the basis of the reported 
age. The birth date for 92 percent of the urban population was established on the basis of their identification card.

The sample used in this paper is based on people living in urban areas, with a known date of birth, and born up to four years before or after the date of eligibility for the transition system (April 1950 to April 1958 for men, and April 1955 to April 1963 for women). The final samples sizes are 129,061 for men and 178,990 for women.

\subsubsection{PILA dataset (2011)}

The PILA dataset is a new dataset designed to collect information from the system used by firms and independent workers to pay for mandated benefits. Since formal-sector workers must be covered by mandated benefits, the dataset collects information for all formal-sector workers, and includes identifiers for employer and employee, basic wage, job location, gender and date of birth (in days) of the employee. The worker's date of birth and gender are added by the Ministry of Health based on the employee's identification card number. This dataset also includes information about firm ownership (public or private) and type of worker (independent or employee). It includes approximately eight million employer-employee pairs per month.

I select information from the entire dataset about all private-sector employees between February and December 2011 (66 percent of total formal employment). Although the dataset incorporates all formal workers, there are some problems with the identification numbers for employers and employees. To avoid false transitions in and out of the dataset, I fill in job spells in cases where an employer-employee match is missing and where the dataset records the same match up to three months before and after. In addition, I drop employees who appear only once in the dataset.

The sample used in this paper is based on all workers who were born up to two years before and after the eligibility threshold (April 1952 to March 1956 for men, and April 1957 to March 1961 for women). The final sample sizes are 964,558 for men (about 88,000 observations per month), and 927,961 for women (about 84,000 observations per month).

\subsubsection{Household Surveys (2006-2011)}

The Colombian Household survey is the official source of employment statistics in Colombia. After a large methodological change in 2006, the dataset includes information about an individual's date of birth (in months), and coverage in terms of pension and contributory health care systems. The surveys also contain information about a worker's earnings and the number of years of contributions made (conditional on contributing). The main limitation of the household surveys for this study is the small sample size for the cohort of interest. The number of observations by birth month in a year is approximately 200 people, and only about 40 people report information regarding years 
of contributions.

The sample used in this paper is based on all urban workers born up to three years before and after the eligibility threshold. The final sample sizes are 12,222 for men and 19,139 for women.

\subsection{Identification strategy}

To identify the effect of pension incentives on the formal labor market outcomes, I use a two-stage approach. In the first stage, I use a regression discontinuity design (RD) to estimate the effect of harder qualifying conditions on labor market outcomes. These estimations provide evidence on the response of formal-sector labor supply to pension incentives, without making further assumptions about workers' earnings and expectations. In the second stage, I use additional assumptions to recover an estimate of the elasticity of the formal-sector labor supply with respect to the net-of-tax share.

\subsubsection{Effect of harder qualifying conditions on labor market outcomes}

To identify the causal link between future pension benefits and formal-sector labor supply, I use a sharp regression discontinuity design. Given a cross-sectional sample of population, I run regressions of the form

$$
Y_{i}=\alpha_{0}+\rho 1_{\left\{D O B_{i} \geq 0\right\}}+\sum_{k=1}^{K}\left(\alpha_{k}+\beta_{k} 1_{\left\{D O B_{i} \geq 0\right\}}\right) \cdot D O B_{i}^{k}+\varepsilon_{i}
$$

where $Y_{i}$ is an indicator of the formal-sector labor supply; $D O B_{i}$ is the normalized date of birth of the individual ( $D O B_{i}=0$ corresponds to the cutoff for harder qualifying conditions); $1_{\left\{D O B_{i} \geq 0\right\}}$ is a treatment indicator equal to one for people born after the cutoff, who are the ones facing harder

qualifying conditions; and $\sum_{k=1}^{K}\left(\alpha_{k}+\beta_{k} 1_{\left\{D O B_{i} \geq 0\right\}}\right) \cdot D O B_{i}^{k}$ is a control function. Based on the reported date of birth, the relevant cutoff for eligibility for the transition system is April 1954 for men and April 1959 for women. Workers born before those dates were eligible for retirement benefits with 1,000 weeks of contributions and at an age of 55 (women) and 60 (men), while workers born after those dates are required to retire two years later (older), and after contributing up to 300 additional weeks.

The identifying assumption in this setup is that unobserved determinants of the formal-sector labor supply evolve smoothly around the eligibility threshold. Under this assumption, $\rho$ can be interpreted as the average effect of harder qualifying conditions on the formal-sector labor supply, defined as

$$
\rho=\lim _{c \downarrow 0} \mathbb{E}\left(Y_{i} \mid D O B_{i}=c\right)-\lim _{c \uparrow 0} \mathbb{E}\left(Y_{i} \mid D O B_{i}=c\right) .
$$


(Imbens and Lemieux, 2008). However, as discussed in Section 3, the response of the formalsector labor supply to changes in minimum qualifying conditions depends on the worker's age $(a)$ and years of contribution $\left(\tau_{a-1}\right)$. Therefore, $\rho$ corresponds to the weighted average of the effect by previous contributions, i.e.,

$$
\rho=\int_{\tau_{a-1}}\left(\lim _{c \downarrow 0} \mathbb{E}\left(Y_{i} \mid D O B_{i}=c, \tau^{\prime}\right)-\lim _{c \uparrow 0} \mathbb{E}\left(Y_{i} \mid D O B_{i}=c, \tau^{\prime}\right)\right) d F_{a}\left(\tau^{\prime}\right),
$$

where $F_{a}(\tau)$ represents the distribution of years of contribution at age $a$.

Since the expected change in qualifying conditions has an ambiguous effect on the formalsector labor supply, the sign of $\rho$ is ambiguous. As discussed in Section 3, the expected effect is positive for workers who are a long way from reaching the new vesting threshold, while it is negative for workers near the new vesting requirement. The sign of the average effect depends on the specific distribution of the number of years of contributions in the population.

Although the distribution of the years of contribution is not observed in the data, the analysis in Section 3 provides useful insights about the expected sign and magnitude of $\rho$. First, $\rho$ should increase with the worker's age, as the distribution of $\tau$ shifts toward higher values of $\tau$ as workers age, putting more weight on the positive effects. Second, $\rho$ should be smaller (in absolute value) for groups of workers with a low probability of finding a formal-sector job. For them, the estimated average effect should be small since they have low long-run gains from searching and a right-skewed distribution of previous contributions. A similar explanation would apply to the result for workers with a high probability of finding a formal-sector job. Workers with a middlerange probability of finding formal-sector jobs are the most responsive to changes in the minimum qualifying conditions.

An additional assumption is required for the estimation of the effects of harder qualifying conditions on formal-sector labor supply for 2011. In 2011, the sample is restricted to the universe of formal-sector workers. Because of that, regression discontinuity estimates are based on counts of formal-sector workers instead of the size of the formal-sector employment relative to the entire population. The identification strategy assumes that the density of the population by birth date evolves smoothly around the eligibility threshold. If so, the estimates based on counts of formalsector employees identify a change in formal-sector employment in response to harder qualifying conditions and not to a change in the population by birth date.

To estimate equation (6), I run regressions separately by gender, as the cohorts affected by the reform are different. I cluster the standard errors by date of birth in months to account for potential misspecification in the control function (Lee and Card, 2008). I also follow the standard practice of testing the sensitivity of the results to the choice of control functions and bandwidth. 


\subsubsection{Labor Supply Elasticity with Respect to the Net-of-Tax Share}

I next measure the incentive effects of pension benefits on the labor supply by calculating the elasticity of labor supply with respect to the net-of-tax share of income (Liebman et al., 2009). This elasticity is a common measure of the efficiency costs of pension policies, as the deadweight loss of the pension tax is proportional to it (Feldstein and Liebman, 2002).

I estimate the elasticity with respect to the net-of-tax share, one minus the effective pension tax rate, along the formal-informal margin, defined as

$$
\sigma=\frac{d \ln L_{a}^{f}}{d \ln \left(1-t_{a}^{e f f}\right)},
$$

where $L_{a}^{f}$ is the formal-sector labor supply for workers of age $a$, and $t_{a}^{e f f}$ is the effective pension tax rate for workers of age $a$,

$$
\begin{aligned}
t_{a}^{e f f} & =t^{\text {nom }}-\beta \frac{\mathbb{E} P W_{a+1}(\tau+1)-\mathbb{E} P W_{a+1}(\tau)}{w} \\
& =t^{\text {nom }}-\beta \frac{\Delta \mathbb{E} P W_{a+1}(\tau+1)}{w} .
\end{aligned}
$$

In the definition of $t_{a}^{e f f}, t^{\text {nom }}$ is the pension tax rate, $\mathbb{E} P W_{a}(\tau)$ stands for the expected pension wealth at age $a$ and $\tau$ years of contribution, and $w$ is the worker's wage. In Section 5.3, I present a detailed discussion of the procedure used to compute the net-of-tax share.

The net-of-tax share measures the net gains from working in the formal sector in the current period. The share takes into account the pension tax rate paid for a worker and the change in the expected pension wealth derived from working an additional period in the formal sector. Based on the results from Section 3, formal-sector labor supply is increasing in the long-run gains from working an additional period in the formal sector. Thus, the expected sign of $\sigma$ is positive.

To estimate $\sigma$, I split the sample into groups characterized by different propensities to work in the formal sector (e.g., by education and region). For each group (denoted by $X$ ), I estimate the average change at the discontinuity of the formal-sector employment $\left(\Delta \ln L_{a X}^{f}\right)$ and compute the average change at the discontinuity of the net-of-tax share $\left(\Delta \ln \left(1-t_{a X}^{e f f}\right)\right)$. Then, I estimate $\sigma$ by running the regression

$$
\Delta \ln L_{a X}^{f}=\alpha_{0}+\sigma \Delta \ln \left(1-t_{a X}^{e f f}\right)+\varepsilon_{X} .
$$

In equation (10), two sources of variation identify $\sigma$ : the variation induced by the change in the minimum qualifying conditions and the variation across groups with different labor market opportunities. 


\section{Estimation results}

\subsection{Identification checks}

The identification strategy relies on the assumption that the unobserved determinants of formalsector labor supply evolve smoothly around the eligibility threshold. This assumption could be undermined in at least two ways: First, workers who are likely to work in the formal sector could manipulate their date of birth in order to appear eligible for the program when they are, in fact, not eligible (McCrary, 2008). Second, the estimated effect of the policy could be confounded by changes in other covariates that might influence the outcome (Imbens and Lemieux, 2008). In this section, I assess these two potential ways in which the identification could be compromised.

I test the manipulation hypothesis by estimating the density of the total population by date of birth above and below the eligibility thresholds, and implementing the test statistic proposed by McCrary (2008). ${ }^{8}$ The results are presented in the top panel of Table 3. The manipulation hypothesis implies that the estimated difference should be negative, as younger workers might change their documentation to appear eligible for the transition system. The estimated effect for men is positive and not significant, supporting the idea that men did not manipulate their date of birth to appear eligible for the transition system. In contrast, the estimated effect for women is positive and significant. Although the sign of the estimated effect for women is the opposite of the expected sign under the manipulation hypothesis, the results raise concerns that population characteristics may change sharply around the discontinuity.

To further test the potential for manipulation by women, I run the McCrary density test with a placebo discontinuity ranging from March 1949 to February 1960. The t-statistics for each month are presented in Figure 5. The t-statistics exhibit two-year cyclical patterns over time, where the largest (absolute) values occur around March and September. The cyclical pattern occurs for both men and women, and the significant effect in March 1959 also occurs in the density for men. Using the regression estimates of the change in the density for men and women born around March 1959, I test whether the changes at the boundary are equal for the density for men and women, and I fail to reject the null hypothesis (p-value 0.394). The results suggest that the sharp change observed in the density of population by date of birth for women is the result of demographic trends and it is not explained by the eligibility for the transition system. Nevertheless, the discontinuity for women suggests to be cautious when interpreting the results for women.

In addition to the manipulation tests, I look for discontinuities at the eligibility thresholds in other observable variables that might explain the worker's labor supply choice. The variables are indicators for whether individuals have a high school diploma or less, whether they report

\footnotetext{
${ }^{8}$ Because the census data are reported by birth month, I run the regressions grouped by date of birth in months and use a bandwidth of 48 months. In all specifications, I use a triangular kernel.
} 
any disability, and whether they identify as members of an ethnic group (black or indigenous). These variables are predetermined by the time the policy change took place and are correlated with the likelihood that an individual has a formal-sector job. Thus, significant differences in these variables would suggest that there are other unobservable factors that may be driving the labor supply decisions around the discontinuity. The bottom panel of Table 3 indicates that there are no significant differences in any of these indicators for either men or women.

Taken together, the results in Table 3 and Figure 5 provide evidence supporting the assumption that other determinants of the formal-sector labor supply evolve smoothly around the eligibility threshold. Although the distribution by date of birth for women is not continuous around the eligibility threshold, the placebo test suggests that the change is caused by time trends other than changes in the pension eligibility. Nonetheless, the interpretation of the results for women must take into account this caveat.

\subsection{Results}

The results of estimating equation (6) are presented in Table 4, and the graphical analysis is presented in Figure 6.

The top panel of Table 4 presents regression discontinuity estimates of the effect of harder qualifying conditions on salaried-formal employment for 2005. I use an indicator of whether the person works as salaried-formal worker as the dependent variable. ${ }^{9}$ Thus, the estimated effect is the average effect of harder qualifying conditions on salaried-formal employment rate. This specification is my preferred specification because it is more robust to changes in the population unrelated to workers' self-selection, a particular concern given the results from the identification checks for women. The middle and bottom panels of Table 4 show the regression discontinuity estimates for the log of the number of salaried-formal workers for 2005 and 2011. The two panels have the advantage of being comparable over time. In all regressions, I use a quadratic polynomial in date of birth as a control function to account for potential non linearities in the formal-sector employment rate, and I use a bandwidth of 48 months for 2005 , and of 730 days for $2011 .^{10}$

The results in Table 4 show that Colombian workers actively responded to changes in the pension incentives. For men, the estimated effect is significant and changes over time. In 2005, the average effect of harder qualifying conditions decreased the salaried-formal employment rate by 2.6 percentage points (on a base of 18 percent). The effect is confirmed by the specification that uses the number of salaried-formal workers for 2005 as dependent variable (panel B of Table 4). The regression discontinuity estimates show that the increase in the number of salaried-formal workers

\footnotetext{
${ }^{9}$ In 2005 , I define a person as a salaried-formal worker when the person worked as a salaried employee, contributed to the pension system, and was covered by the contributory health care system.

${ }^{10}$ The Imbens and Kalyanaraman (2012) optimal bandwidth for the 2005 regression is 55 months.
} 
at the discontinuity is negative 12 percent. In 2011, the estimated average effect on salaried-formal employment for men is positive and significant, implying an increase of 6.8 percent. The results are robust to the definition of formal worker, and to the choice of control functions, bandwidth, estimators, and controls (Tables 11 to 13 in the Appendix).

The results for men are consistent with the framework presented above, in which the average effect of harder qualifying conditions depends on the worker's age. Table 4 presents information about the distribution of the years of contribution for workers born around the eligibility threshold, based on the household surveys for 2006 and 2011. ${ }^{11}$ Since workers accumulate more years of experience in the formal sector as they age, the distribution of years of contribution is more concentrated on values above 20 years in 2011 than in 2005. As a result, the average effect for 2011 should be greater than the average effect for 2005, given that fewer eligible workers have long-run incentives to search for formal-sector jobs, as they already met the vesting requirement.

The results for women are intriguing. The 2005 estimates do not show any sizable or significant response. For 2011, however, Table 12 shows significant results, depending on the specification. Since the 2011 results are not normalized by the population by date of birth, it is not possible to disentangle the potential effect of changes in the policy from the documented changes in the total population around the discontinuity. One explanation for the lack of response by women is that the transition system required workers to have already contributed to the pension system by 1994 . This condition limited the applicability of the reform for women because of their relatively low labor force participation prior to this time (62 percent from 1984 to 1993$).^{12}$

General equilibrium. To address the general equilibrium response to changes in pension incentives, I estimate the effect of harder qualifying conditions on the wages of formal-sector workers in 2011. If firms are able to set different wages between workers, wages offset part of the longrun gains from a formal-sector job. Therefore, the expected sign of the average effect of harder qualifying conditions on wages is the opposite to the sign of the average effect on employment. The estimates for the formal-sector wages are presented in the top panel of Table 5. The average effect of harder qualifying conditions on formal-sector wages is about negative 3 percent for men and is not significant for women (columns (1) and (5)). Since the effect on employment is positive in 2011, the result on average wages suggests that part of the workers additional search effort is offset by a change in wages.

To understand the sources of the aggregate results, I estimate the average effect of harder qualifying conditions on formal-sector wages and employment by wage range. The results are presented in the bottom panel of Table 5. Consistent with the analytical framework used here, low-wage men

\footnotetext{
${ }^{11}$ The distribution is conditional on making contributions.

${ }^{12}$ Between 1984 and 1993, the labor force participation rate for men around the discontinuity threshold was 97 percent.
} 
are the most responsive to changes in pension incentives. This occurs for two reasons. First, lowwage workers are more likely to find the minimum qualifying conditions binding. Second, the replacement rate for low-wage workers is close to one. As a result, they do not have additional long-run gains from working in the formal sector once they meet the requirements. The response from women is not significant.

The top panel of Table 5 presents the average effect of harder qualifying conditions on formalsector wages by wage range. For men, the estimated effects are small and not significant. The difference relative to the aggregate results is driven by a composition effect, as the number of workers earning the minimum wage is larger for younger workers (panel B of Table 5). Because the change of the minimum wage around the discontinuity is zero, the average effect on wages goes down. Thus, the results indicate that the impact of the policy change on wages was limited.

Nonetheless, the results presented in Table 5 do not rule out the possibility that changes in pension benefits are offset by changes in wages. The regression discontinuity estimates are intended to identify differential changes in the wages around the eligibility threshold. If the response in wages is associated with spillover effects, the estimates presented above are a lower bound of the actual response of the formal-sector labor supply to pension incentives.

Composition effects. I complement the analysis by testing the effect of pension incentives on the composition of the labor force. Based on information from 2005, I run versions of equation (6) for indicators of whether the worker is self-employed, whether the worker works as a salaried-informal worker, and whether the worker is in the labor force.

The estimation results are presented in Table 6, while the graphical evidence for men is presented in Figure 6. The reduction in the salaried-formal employment for men is associated with increases in informal-sector employment, in particular self-employment. The regression discontinuity estimate for the self-employment indicator is of the same magnitude but opposite sign as that of the estimate for the salaried-formal employment indicator. In contrast, the estimates using salaried-informal and labor force participation indicators as dependent variables are not significant. For women, there is no significant response in labor force participation or type of employment. Similar results have been noted in the literature concerned with the effect of mandated pension benefits on formal-sector labor supply. For instance, Almeida and Carneiro (2012) found that higher mandated benefits with no wage adjustment generate an incentive for Brazilian selfemployed workers to switch to salaried-formal jobs.

Heterogeneity analysis. In this section, I analyze the differential effect of harder qualifying conditions on formal-sector labor supply for different groups. Because not all groups exhibit the same propensity to work in the formal sector, the group analysis provides evidence on the mechanisms 
driving the aggregate results.

I estimate the response of the formal-sector labor supply to changes in pension incentives for subsamples. To estimate this response, I group workers according to three demographic characteristics: educational attainment, household composition (e.g., presence of a spouse in the household), and region. In what follows, I present the results for men. The results for women are not significant and may be affected by changes in the distribution of population by date of birth. Due to data availability, I present the results for educational attainment and household characteristics for 2005 , and the regional results for 2005 and 2011.

The first set of results is for workers grouped according to educational attainment. Lesseducated workers are more likely to react to pension incentives for two reasons. First, these workers face higher replacement rates with no incentives to contribute beyond the vesting period. Second, they face lower formal-sector employment rates, which makes the condition for minimum years of contribution binding.

The estimation results show that the effect of harder qualifying conditions is concentrated among workers with secondary education (Table 7$).{ }^{13}$ For workers with secondary education, harder qualifying conditions reduced the salaried-formal employment rate by 9 percentage points (on a 21 percent basis). In contrast, the estimated effects for workers with primary or postsecondary education are smaller and not significant. The third column of Table 7 shows the average salaried-formal employment rate by educational attainment. Consistent with the theoretical framework set out in this paper, workers with low or high informality rates are less responsive to changes in pension benefits.

The second set of results is for workers grouped according to the composition of the household. I analyze the response of workers in households with different incentives to search for formalsector jobs. The samples are defined according to the person's marital status and whether the person is living in a household with only one member in the labor force. Married men and men living in a household with only one member in the labor force should respond more actively to harder qualifying conditions. First, men tend to get married to younger women (the median difference is 5 years). Given that the survivor pension rate is 100 percent, the long-run benefits of getting a pension are higher for households with married couples. Second, men living in households with only one member in the labor force may have limited family support after retirement. A concern with this part of the analysis is that the variables used to select the samples are endogenous to the eligibility for the transition system. However, I find no evidence that household structure changes as result of harder qualifying conditions (Table 8).

\footnotetext{
${ }^{13} \mathrm{My}$ implicit assumption is that workers do not change their schooling as response to the change in the pension qualifying conditions. Since men at the eligibility cutoff were 40 years old when the reform took place, this assumption seems reasonable and is consistent with the evidence presented in the identification checks (Table 3).
} 
Table 9 reports the results for the different subsamples. The effect of pension incentives varies systematically depending on household characteristics. The response is concentrated among married men, and among households where there is only one member in the labor force.

The third set of results is for workers grouped according to region. Institutional factors and economic development generate differential formal-sector patterns by region (La Porta and Shleifer, 2014). The regional differences provide additional evidence on the relationship between the labor supply response to pension incentives and the labor market opportunities.

Table 10 reports the regression discontinuity estimates by region for 2005 and 2011. I group workers based on their departments' (provinces') GDP per capita excluding oil. The developed departments are Bogota-Cundinamarca, Antioquia, and Valle, and the developing departments comprise the rest of the country. The developed regions represent about 60 percent of the total GDP and 45 percent of total population in 2005. The average response to changes in the pension benefits is large and significant for developed regions, which offer most of the formal-sector employment.

In summary, the results presented in this section support the view that the formal-sector labor supply responds to pension incentives. The estimated average responses of formal-sector labor supply to harder qualifying conditions are heterogeneous and depend on labor market opportunities for the worker. The effect is concentrated among workers for whom the minimum qualifying conditions for retirement are binding, workers having higher expected pension wealth, and workers in households with only one member in the labor force.

\subsection{Elasticity of formal-sector labor supply with respect to the net-of-tax share}

To compute the elasticity of the formal-sector labor supply with respect to the net-of-tax share $(\sigma)$, first I compute the average change in the net-of-tax share at the discontinuity for selected samples. Next, I recover the elasticity by regressing the estimates of average changes in formalsector employment on average changes in the net-of-tax share.

To estimate $\sigma$, first I compute the net-of-tax share for subsamples of workers with different propensities to work in the formal sector. These subsamples are defined according to region and educational attainment for 2005, and region and wage range for 2011 (12 groups). ${ }^{14}$ For each subsample (denoted by $X$ ), I compute the average change in the net-of-tax share at the discontinuity. To do this, I construct a grid for the expected pension wealth for every combination of age $a$ and years of contribution $\tau, \mathbb{E}_{X} P W_{a}(\tau)$. I assume that the worker will retire as soon as he meets the

\footnotetext{
${ }^{14}$ For 2005, I grouped workers according to their place of residence (developed and developing regions) and their educational attainment (primary, secondary and postsecondary education) for 6 groups in total. For 2011, I grouped workers according to their place of work (developed and developing regions) and their wage range $(1,1-2$, and 2+ times the minimum wage) for another 6 groups.
} 
conditions for retirement, and that he will enjoy the pension benefits until age 80 . The conditions and benefits that the worker receives after retirement are defined by the pension system. If the worker does not meet the retirement conditions by age 65 , he will ask for a refund of his contributions to date. For the refund of contributions, I assume that the average contribution rate of a worker over his lifetime is 10 percent, as the pension contribution rate before 1994 was 6.5 percent of the worker's wage. If the worker does not retire, the worker will work an additional period in the formal sector with probability $p_{X}(a)$.

Next, I compute the change in the log net-of-tax share at the discontinuity as

$$
\begin{aligned}
\Delta \ln \left(1-t_{a \tau^{\prime} X}^{e f f}\right)= & \ln \left(1-t^{n o m}+\frac{\beta \Delta \mathbb{E}_{X} P W_{a+1}^{S I}\left(\tau^{\prime}+1\right)}{w_{X}}\right) \\
& -\ln \left(1-t^{n o m}+\frac{\beta \Delta \mathbb{E}_{X} P W_{a+1}^{T}\left(\tau^{\prime}+1\right)}{w_{X}}\right) .
\end{aligned}
$$

where the superscripts $S I$ and $T$ denote that the expected pension wealth is computed using the conditions of the transition and the social insurance systems. I assume a pension tax rate of 4 percent, the contribution paid by salaried-formal workers. ${ }^{15}$ Given that the estimates of the changes in employment are observed for men in 2005 and 2011, I compute the change in the log net-of-tax share for workers at age 51 and 57 (the age of the eligible men at the cutoff in 2005 and 2011). Finally, using information about the distribution of the number of years of contribution for the group $X$ at age $a, F_{a X}(\tau)$, I compute the average change of the log net-of-tax share along the formal-informal margin as

$$
\Delta \ln \left(1-t_{a X}^{e f f}\right)=\sum_{\tau^{\prime}} \Delta \ln \left(1-t_{a \tau^{\prime} X}^{e f f}\right) d F_{a X}\left(\tau^{\prime}\right) .
$$

In the calculation of $\Delta \ln \left(1-t_{a X}^{e f f}\right)$, I estimate $p_{X}(a)$ from the 2005 census and $F_{a X}(\tau)$ from the household surveys of 2006 and 2011. Moreover, I assume that $w_{X}$ is constant over time and I set it to twice the minimum wage for skilled workers and to the minimum wage for the other groups. ${ }^{16}$

For the second stage of the estimation of $\sigma$, I regress the changes in the formal-sector employment on the change of the net-of-tax share. Figure 8 displays a scatterplot with the average changes in log employment (vertical axis) and in net-of-tax share (horizontal axis) at the discontinuity. The groups from 2005 and 2011 are represented by triangles and circles, respectively. Consistent with

\footnotetext{
${ }^{15}$ In Colombia, the pension tax rate for all workers is 16 percent of the monthly wage. Since for salaried workers the employer pays 12 percentage points, I am assuming that the employers cannot pass through the additional contribution to lower wages. This is likely the case for minimum wage workers. The results are not sensitive to changes in the pension tax rate.

${ }^{16}$ The skilled workers are workers with post-secondary education for 2005 and workers with wages above twice the minimum wage for 2011.
} 
the predictions of the model, workers with stronger pension incentives along the formal-informal margin also exhibit stronger responses in their formal-sector labor supply. A linear regression on these points yields an estimated elasticity of $\sigma=1.66$. The estimated elasticity is slightly larger than the values of the same regression when restricted to cross through the origin $(\sigma=1.60)$ and the median value of the elasticity by group $(\sigma=1.47)$. Regardless of the estimator used, the implied values of $\sigma$ are estimated with low precision.

The implied value of $\sigma$ is likely a lower bound of the actual elasticity for at least three reasons. First, the estimates of changes in the formal-sector labor supply do not account for spillover effects, for instance, offsetting effects of wages affecting workers born before and after the eligibility threshold. Second, because of the definition of the transition system, a fraction of the population could not take up the benefits (Section 2.2). Third, $\Delta \ln \left(1-t_{a X}^{e f f}\right)$ may over-estimate the actual change in the net-of-tax share along the formal-informal margin. In particular, $\Delta \ln \left(1-t_{a X}^{e f f}\right)$ would be smaller (and $\sigma$ larger) if workers have a lower discount rate $\beta$ or worker's utility function is concave (Stock and Wise, 1990).

\section{Final remarks}

In this paper, I show that workers take into account their future pension benefits when it comes to making their labor supply decisions. Using the Colombian pension system, I show that a change in future pension benefits generates a large shift between the formal-sector and informal-sector labor supply. In contrast, there is no effect on labor force participation. The response is heterogeneous and depends on the worker's age, employment history, and opportunities to find formal-sector jobs. Using additional assumptions, I obtain an elasticity of formal-sector labor supply with respect to the net-of-tax share of 1.7 .

Although the estimation results cannot be generalized to other cohorts or to other countries, the results suggest that the behavioral response to pension incentives may be large. Workers' behavioral responses should be taken into account in the design of pension programs, as such responses may create large efficiency costs. In particular, pension programs that reduce the value of the expected pension benefits have a negative effect on formal-sector labor supply. From a fiscal perspective, the effect of such programs is twofold. On the revenue side, these programs reduce the revenue achieved by way of contributions to the pension system, since fewer workers contribute. On the expenditure side, these programs increase the future expenditure in assistance programs, since more retirees would claim non-contributory pension benefits.

Nevertheless, a comprehensive evaluation of pension programs must take into account other factors that may mitigate their efficiency costs. For example, the welfare gains from the insurance against consumption losses after retirement may be significant. Additionally, the overall effect 
of pension programs depends on which sector of the population is affected. For instance, noncontributory pension programs for workers with low opportunities of finding formal-sector jobs could be welfare enhancing. For these workers, the behavioral response is small and the extra gains from insurance may be large.

\section{References}

Rita Almeida and Pedro Carneiro. Enforcement of labor regulation and informality. American Economic Journal: Applied Economics, 4(3):64-89, July 2012.

Mariano Bosch, Ángel Melguizo, and Carmen Pagés. Better Pensions, Better Jobs: Towards Universal Coverage in Latin America and the Caribbean. IADB, 2013.

Raj Chetty. A general formula for the optimal level of social insurance. Journal of Public Economics, 90(10-11):1879-1901, 2006.

Martin Feldstein and Jeffrey B. Liebman. Social Security. In Handbook of Public Economics, volume 4, pages 2245 - 2324. Elsevier, 2002.

Markus Frölich, David Kaplan, Carmen Pagés, Jamele Rigolini, and David Robalino. Social Insurance, Informality, and Labour Markets: How to Protect Workers While Creating Good Jobs. Oxford University Press, 2014.

Francois Gerard and Gustavo M. Gonzaga. Informal labor and the cost of social programs: Evidence from 15 years of unemployment insurance in Brazil. Unpublished Manuscript, 2014.

Guido Imbens and Karthik Kalyanaraman. Optimal bandwidth choice for the regression discontinuity estimator. The Review of Economic Studies, 79(3):933-959, 2012.

Guido W Imbens and Thomas Lemieux. Regression discontinuity designs: A guide to practice. Journal of Econometrics, 142(2):615-635, 2008.

Rafael La Porta and Andrei Shleifer. Informality and development. Journal of Economic Perspectives, 28(3):109-26, 2014.

David S Lee and David Card. Regression discontinuity inference with specification error. Journal of Econometrics, 142(2):655-674, 2008.

S. Levy. Good intentions, bad outcomes: Social policy, informality, and economic growth in Mexico. Brookings Inst Press, 2008. 
Jeffrey B. Liebman, Erzo F.P. Luttmer, and David G. Seif. Labor supply responses to marginal social security benefits: Evidence from discontinuities. Journal of Public Economics, 93(1112):1208-1223, 2009.

Jorge Llano, Jaime Cardona, Natalia Guevara, Gonzalo Casas, Camilo Arias, and Fernando Cardozo. Movilidad e Interacción entre Regímenes del Sistema General de Pensiones Colombiano. Technical report, Ministry of Finance, 2013.

William F Maloney. Informality revisited. World Development, 32(7):1159 - 1178, 2004. ISSN 0305-750X.

Justin McCrary. Manipulation of the running variable in the regression discontinuity design: A density test. Journal of Econometrics, 142(2):698 - 714, 2008. The regression discontinuity design: Theory and applications.

Guillermo E. Perry, William F. Maloney, Omar S. Arias, Pablo Fajnzylber, Andrew D. Mason, and Jaime Saavedra-Chanduvi. Informality: Exit and exclusion. World Bank Publications, 2007.

Emmanuel Saez, Manos Matsaganis, and Panos Tsakloglou. Earnings determination and taxes: Evidence from a cohort-based payroll tax reform in Greece. The Quarterly Journal of Economics, 127(1):493-533, 2012.

Mauricio Santa María, Roberto Steiner, Jorge Humberto Botero, Mariana Martinez, Natalia Millán, Maria Alejandra Arias, and Erika Schutt. El Sistema Pensional en Colombia: Retos y Alternativas para Aumentar la Cobertura (Informe Final). Technical report, Fedesarrollo, 2010.

James H. Stock and David A. Wise. Pensions, the option value of work, and retirement. Econometrica, 58(5):pp. 1151-1180, 1990.

Lawrence H. Summers. Some simple economics of mandated benefits. The American Economic Review, 79(2):pp. 177-183, 1989. 
Table 1: Labor market composition and average wages, Colombia, 2011

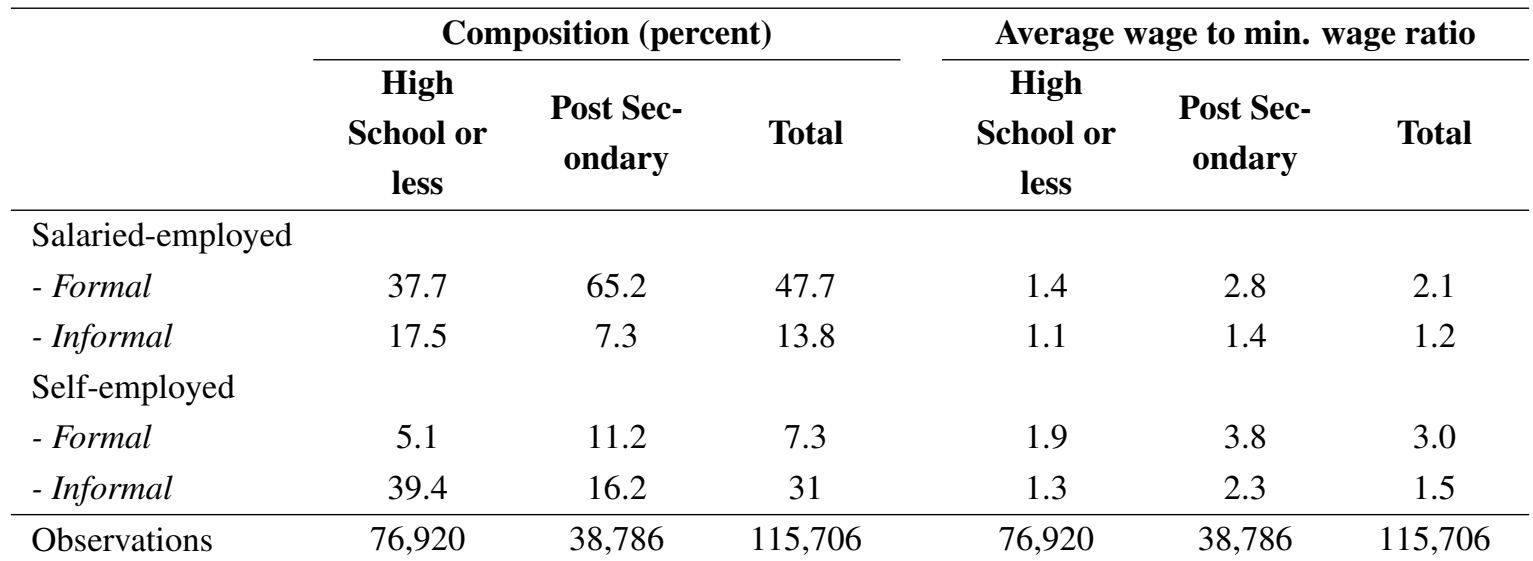

Notes: The table reports the composition and average wages of urban workers aged 20 to 65 working at least 30 hours per week. To avoid the effect of outliers and misreported information in the wage distribution, I trim the top 1 percent of workers of the wage distribution, and workers with wages below 40 percent of the minimum wage. A formal worker is defined as a worker who is making contributions to the pension system and is covered by the contributory health care system. Source: Colombian Household Surveys, 2011 
Table 2: General Pension System characteristics

\begin{tabular}{|c|c|c|c|}
\hline & Transition & Social Insurance & Individual Account \\
\hline Managed by & Colpensiones & Colpensiones & Private pension funds \\
\hline Type of system & Defined benefit & Defined benefit & Defined contribution \\
\hline Eligibility & $\begin{array}{l}\text { Workers born before } \\
\text { April } 1959 \text { (women) or } \\
\text { April } 1954 \text { (men) with } \\
750 \text { weeks of } \\
\text { contributions by July } \\
2005 .^{\dagger}\end{array}$ & $\begin{array}{l}\text { All public and privat } \\
\text { (including self-employe } \\
\text { the transition }\end{array}$ & $\begin{array}{l}\text { sector workers } \\
\dagger \text { ) not eligible for } \\
\text { ystem. }\end{array}$ \\
\hline $\begin{array}{l}\text { Qualifying } \\
\text { conditions }\end{array}$ & $\begin{array}{l}\text { Private sector workers: } \\
55 \text { years (women), } 60 \\
\text { years (men) AND 1,000 } \\
\text { weeks of contributions } \\
\text { in any time. } \\
\text { Public workers: } 50 \text { years } \\
\text { (women), } 55 \text { years } \\
\text { (men), AND } 20 \text { years of } \\
\text { service. }\end{array}$ & $\begin{array}{l}\text { All workers: } 55 \text { years } \\
\text { (women), } 60 \text { years } \\
\text { (men) AND } 1,050 \text { to } \\
1,300^{\dagger \dagger \dagger} \text { weeks of } \\
\text { contributions in any } \\
\text { time. Starting in } 2014 \text {, } \\
\text { minimum age increased } \\
\text { by two years to } 57 \text { for } \\
\text { women and } 62 \text { for men. }\end{array}$ & $\begin{array}{l}\text { All workers: Enough } \\
\text { capital to buy an annuity } \\
\text { of } 1.1 \text { minimum wages, } \\
\text { OR } 57 \text { years (women), } \\
62 \text { years (men) and } \\
1,150 \text { weeks of } \\
\text { contributions in any } \\
\text { time for an annuity of a } \\
\text { minimum wage. }\end{array}$ \\
\hline Contribution & \multicolumn{3}{|c|}{$16 \%$ of wage $-11.5 \%$ contribution, $4.5 \%$ for administrative fees and insurance } \\
\hline Employer payment & \multicolumn{3}{|c|}{ Salaried workers: 3/4 employer - 1/4 employee. Self-employed 100\% } \\
\hline
\end{tabular}


General Pension System characteristics (continued)

\begin{tabular}{|c|c|c|c|}
\hline & Transition & Social Insurance & Individual Account \\
\hline Replacement rate & $\begin{array}{l}\text { Function of length of } \\
\text { contributions. From } \\
65 \% \text { to } 85 \% \text { (See Figure } \\
2 \text { ) }\end{array}$ & $\begin{array}{l}\text { Function of length of } \\
\text { contributions and wage. } \\
\text { From } 65 \% \text { to } 85 \% \text { (See } \\
\text { Figure } 2 \text { ). }\end{array}$ & $\begin{array}{l}\text { It depends only on the } \\
\text { accrued capital }\end{array}$ \\
\hline Pension range & $\begin{array}{l}\text { At least } 1 \text { Minimum } \\
\text { wage }\end{array}$ & 1-25 Minimum wages & $\begin{array}{l}\text { At least } 1 \text { Minimum } \\
\text { wage }\end{array}$ \\
\hline Survivor benefits & 100 percent & 100 percent & 100 percent \\
\hline $\begin{array}{l}\text { Contributions } \\
\text { refund }\end{array}$ & \multicolumn{2}{|c|}{ Contributions adjusted by inflation } & $\begin{array}{l}\text { Accrued capital + } \\
\text { interest }\end{array}$ \\
\hline \multicolumn{4}{|c|}{ Coverage Statistics (2005) - Millions } \\
\hline Total & \multicolumn{2}{|c|}{5.67} & 5.95 \\
\hline 1-2 Min. wage & \multicolumn{2}{|c|}{5.22} & 5.08 \\
\hline Aged $45+$ & \multicolumn{2}{|c|}{2.35} & 0.67 \\
\hline Retirees & \multicolumn{2}{|c|}{0.82} & 0.02 \\
\hline
\end{tabular}

Notes: ${ }^{\dagger}$ The limit of 750 weeks of contributions by July 2005 was introduced in 2005 . ${ }^{\dagger \dagger}$ Contributions for Self-employed workers become compulsory since January 2003. ${ }^{\dagger \dagger \dagger}$ Starting in 2003, the length of contributions needed to qualify for a pension increased gradually from 1,000 weeks in 2004 up to 1,300 weeks in 2015. Coverage statistics taken from the Superintendencia Financiera website.

Source: Santa María, Steiner, Botero, Martinez, Millán, Arias, and Schutt (2010), Llano, Cardona, Guevara, Casas, Arias, and Cardozo (2013) and texts of the reforms. 
Table 3: Identification checks, 2005

\section{A: McCrary's density test}

\begin{tabular}{lcc}
\hline & Men & Women \\
\hline Test Statistic & 0.024 & 0.078 \\
(Bandwidth 48 months) & {$[0.033]$} & {$[0.025]^{* * *}$} \\
\hline Observations & 126,095 & 175,047 \\
\hline
\end{tabular}

B: Balance tests (estimates scaled up by 100)

\begin{tabular}{lcc}
\hline High School or less indicator & 0.68 & 0.25 \\
(Bandwidth 48 months) & {$[1.21]$} & {$[1.12]$} \\
Disability indicator & -0.21 & 0.48 \\
(Bandwidth 48 months) & {$[1.03]$} & {$[0.71]$} \\
Ethnical minority indicator & -0.13 & 0.99 \\
(Bandwidth 48 months) & {$[0.74]$} & {$[0.64]$} \\
\hline Observations & 78,655 & 110,626 \\
\hline
\end{tabular}

Notes: The Table presents estimates for testing factors that affect the validity of the identification assumptions required for the regression discontinuity design described in Section 4.2.1. The top panel presents the estimation results by gender for the test proposed by McCrary (2008), to test potential discontinuities in the density of the running variable (population by date of birth). The bottom panel presents RD estimates for observable determinants of formalemployment and other predetermined variables, to gather evidence about other potential changes that may confound the estimated effect of the policy. Each cell reports an RD estimate based on a separate regression of a variable predetermined by the time of the introduction of the policy as dependent variable versus a quadratic polynomial on date of birth and its interaction with a dummy for being born after March-54 (men) and March-59 (women) as independent variables (See equation (6)). The selected variables are indicator variables for whether the person's has a high school diploma or less, whether the person reports any disability, and whether the person identifies himself as a member of a ethnic group (black or indigenous). Regressions were computed using the IPUMS Colombian Census dataset. Standard errors clustered by date of birth (in months) in brackets. ${ }^{*} \mathrm{p}<0.1,{ }^{* *} \mathrm{p}<0.05,{ }^{* * *} \mathrm{p}<0.01$. 
Table 4: RD estimation results, 2005 and 2011

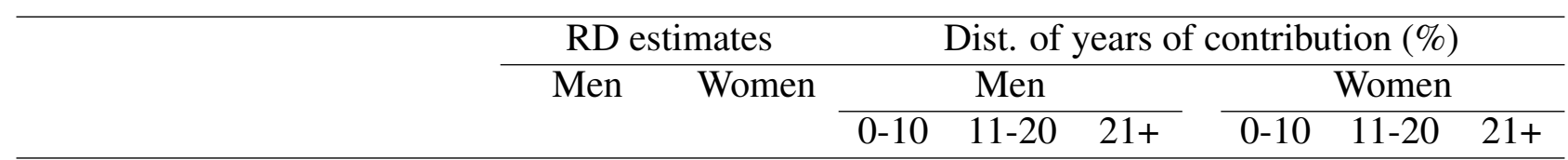

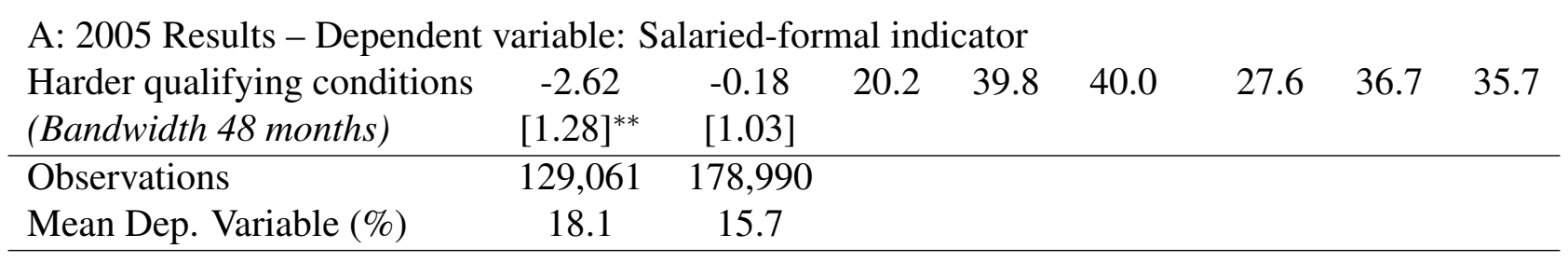

B: 2005 Results - Dependent variable: Log salaried-formal workers by date of birth in months

\begin{tabular}{lcccccccc} 
Harder qualifying conditions & -11.9 & 8.53 & 20.2 & 39.8 & 40.0 & 27.6 & 36.7 & 35.7 \\
(Bandwidth 48 months) & {$[8.65]$} & {$[7.60]$} & & & & & & \\
\hline Observations & 15,349 & 20,616 & & & & & & \\
\hline
\end{tabular}

C: 2011 Results - Dependent variable: Log salaried-formal workers by date of birth in days

\begin{tabular}{lcccccccc} 
Harder qualifying conditions & 6.79 & 2.03 & 13.0 & 31.6 & 55.5 & 20.8 & 37.6 & 41.5 \\
(Bandwidth 48 months) & {$[2.39]^{* * *}$} & {$[2.17]$} & & & & & & \\
\hline Observations & 964,558 & 927,691 & & & & & & \\
\hline
\end{tabular}

Notes: All estimates scaled up by 100. Each cell reports an RD estimate based on a separate regression of a labor market indicator on a quadratic polynomial on date of birth and its interaction with a dummy for being born after March-54 (men) and March-59 (women) as independent variables (See equation (6)). Panel A includes the total population and uses as dependent variable an indicator variable of whether the person is a salaried worker making contributions to the pension system and being covered by the contributory health care system - so the RD estimate is an effect on the salaried-formal employment rate. Panels B and C report the RD estimates of regressions in which the dependent variable is the log number of salaried-formal workers for 2005 and 2011 . Regressions were estimated using the Colombian Census long-form questionnaire dataset (2005) and the PILA dataset (2011). Standard errors clustered by date of birth (in months) in brackets. * $p<0.1,{ }^{* *} p<0.05,{ }^{* * *} p<0.01$. The distribution of years of contribution is conditional on making contributions, and it is based on the Household Surveys data of 2006 and 2011 . 
Table 5: RD estimation results for wages in the formal sector, 2011

\begin{tabular}{lcccccccc}
\hline & \multicolumn{4}{c}{ Men } & \multicolumn{7}{c}{ Women } \\
\cline { 2 - 10 } & All & At $W_{m}$ & $1-2 W_{m}$ & $2+W_{m}$ & All & At $W_{m}$ & $1-2 W_{m}$ & $2+W_{m}$ \\
& $(1)$ & $(2)$ & $(3)$ & $(4)$ & $(5)$ & $(6)$ & $(7)$ & $(8)$ \\
\hline \\
A: RD Estimates for log wages (estimates scaled up by 100) & & & & & \\
Harder qualifying conditions & -3.11 & - & -0.25 & -1.51 & 1.14 & - & 0.23 & 1.2 \\
(Bandwidth 730 days) & {$[0.82]^{* * *}$} & & {$[0.56]$} & {$[1.46]$} & {$[1.51]$} & {$[0.83]$} & {$[1.85]$} \\
\hline Observations & 964,558 & 416,927 & 287,659 & 259,972 & 927,691 & 365,667 & 321,405 & 240,619 \\
\hline
\end{tabular}

B: RD Estimates for log number of workers (estimates scaled up by 100)

\begin{tabular}{lcccccccc} 
Harder qualifying conditions & 6.79 & 10.51 & 7.22 & 0.39 & 2.03 & 0.98 & 1.95 & 4.99 \\
(Bandwidth 730 days) & {$[2.39]^{* * *}$} & {$[3.36]^{* * *}$} & {$[2.03]^{* * *}$} & {$[3.03]$} & {$[2.17]$} & {$[3.41]$} & {$[3.47]$} & {$[3.84]$} \\
\hline Observations & 964,558 & 416,927 & 287,659 & 259,972 & 927,691 & 365,667 & 321,405 & 240,619 \\
\hline
\end{tabular}

Notes: Each cell reports an RD estimate based on a separate regression of a labor market indicator on a quadratic polynomial on date of birth and its interaction with a dummy for being born after March-54 (men) and March-59 (women) as independent variables (See equation (6)). Panel A includes salaried-formal workers for 2011 and reports the RD estimates using as dependent variable the log monthly wage of formal workers. Columns (1) and (5) presents the results for the full sample, while columns (2) to (4) and (6) to (8) show the results for subsamples defined by wage range. By construction, the difference at the discontinuity for workers at the minimum wage is zero. Panel B reports the RD estimates of regressions in which the dependent variable is the log number of salaried-formal workers for 2011 following the same sample selections than panel A. Regressions were estimated using the PILA dataset. Standard errors clustered by date of birth (in months) in brackets. $* \mathrm{p}<0.1, * * \mathrm{p}<0.05, * * * \mathrm{p}<0.01$. 
Table 6: Estimation results for other labor market outcomes, 2005

A: RD estimates for other labor market outcomes - Men, 2005

Estimates scaled up by 100

\begin{tabular}{lcccc}
\hline & $\begin{array}{c}\text { Lab. Force } \\
\text { participation }\end{array}$ & $\begin{array}{c}\text { Salaried } \\
\text { formal }\end{array}$ & $\begin{array}{c}\text { Salaried } \\
\text { informal }\end{array}$ & $\begin{array}{c}\text { Self- } \\
\text { employed }\end{array}$ \\
\hline Harder qualifying conditions & 1.20 & -2.62 & 0.21 & 2.49 \\
(Bandwidth 48 months) & {$[1.39]$} & {$[1.28]^{* *}$} & {$[1.47]$} & {$[1.33]^{*}$} \\
\hline Observations & 129,061 & 129,061 & 129,061 & 129,061 \\
Mean dep. variable $(\%)$ & 78.3 & 18.1 & 27.3 & 25.7 \\
\hline
\end{tabular}

B: RD estimates for other labor market outcomes - Women, 2005

Estimates scaled up by 100

\begin{tabular}{lcccc}
\hline & $\begin{array}{c}\text { Lab. Force } \\
\text { participation }\end{array}$ & $\begin{array}{c}\text { Salaried } \\
\text { formal }\end{array}$ & $\begin{array}{c}\text { Salaried } \\
\text { informal }\end{array}$ & $\begin{array}{c}\text { Self- } \\
\text { employed }\end{array}$ \\
\hline Harder qualifying conditions & -0.69 & -0.18 & -0.86 & 0.68 \\
(Bandwidth 48 months) & {$[1.76]$} & {$[1.03]$} & {$[1.32]$} & {$[0.93]$} \\
\hline Observations & 178,990 & 178,990 & 178,990 & 178,990 \\
Mean dep. variable $(\%)$ & 49.7 & 15.7 & 18.9 & 10.9 \\
\hline
\end{tabular}

Notes: Each cell reports an RD estimate based on a separate regression of a different labor market indicator on a quadratic polynomial on date of birth and its interaction with a dummy for being born after March-54 (men) and March-59 (women) as independent variables (See equation (6)). The columns labeled salaried-formal present the baseline RD estimates presented in Table 4. The additional columns reports results of RD estimates for labor force participation, salaried-informal employment, and self-employment rate. Regressions were estimated using the Colombian Census long-form questionnaire dataset. Standard errors clustered by date of birth (in months) in brackets. * $\mathrm{p}<0.1, * * \mathrm{p}<0.05, * * * \mathrm{p}<0.01$. 
Table 7: Estimation results by educational attainment - Men, 2005

A: 2005 Results - Dependent variable: Salaried-formal employment indicator (Estimates scaled up by 100)

\begin{tabular}{lccccc}
\hline & RD & Sal-formal & \multicolumn{3}{c}{ Dist. of years of contribution (\%) } \\
& Estimate & emp. rate & $0-10$ & $11-20$ & $21+$ \\
\hline Primary & -0.16 & 10.6 & 29.3 & 35.6 & 35.1 \\
$\begin{array}{l}\text { (Bandwidth 48 months) } \\
\text { Secondary }\end{array}$ & {$[1.58]$} & & & & \\
(Bandwidth 48 months) & -9.32 & 21.2 & 26.3 & 40.8 & 33.0 \\
$\begin{array}{l}\text { Post-Secondary } \\
\text { (Bandwidth 48 months) }\end{array}$ & -0.82 & 38.4 & 8.0 & 41.5 & 50.5 \\
\hline Observations & $12.91]$ & & & & \\
Mean dep. variable (\%) & 18.061 & & & & \\
\hline
\end{tabular}

Notes: The first column reports RD estimates based on a separate regression of the salaried-formal employment indicator on a quadratic polynomial on date of birth and its interaction with a dummy for being born after March-54 (men) and March-59 (women) as independent variables and educational attainment. The cells report the average effect of harder qualifying conditions by educational attainment (primary or less, secondary or at least some secondary, and post-secondary). Regressions were estimated using the Colombian Census long-form questionnaire dataset. Standard errors clustered by date of birth (in months) in brackets. * $\mathrm{p}<0.1, * * \mathrm{p}<0.05, * * * \mathrm{p}<0.01$. The distribution of years of contribution is conditional on making contributions, and it is based on the Household Surveys data of 2006 and 2011. 
Table 8: RD results for indicators of household characteristics, 2005

\begin{tabular}{lcc} 
(Estimates scaled up by 100) & & \\
\hline Dependent variable & Married & $\begin{array}{c}\text { Only worker } \\
\text { in household }\end{array}$ \\
\hline Harder qualifying conditions & 0.42 & -2.08 \\
(Bandwidth 48 months) & {$[1.44]$} & {$[1.49]$} \\
\hline Observations & 110,174 & 106,811 \\
Mean dep. variable (\%) & 83.1 & 38.7 \\
\hline
\end{tabular}

Notes: Each cell reports an RD estimate based on a separate regression of the household composition indicator on a quadratic polynomial on date of birth and its interaction with a dummy for being born after March-54 (men) and March-59 (women) as independent variables (See equation (6)). The first column presents RD estimates using as dependent variable an indicator variable for marital status ( 1 if married, 0 otherwise). The second column restricts the sample to households with at least one person in the labor force, and estimates the model using as dependent variable an indicator for being the only member of the household in the labor force. Regressions were estimated using the Colombian Census long-form questionnaire dataset. Standard errors clustered by date of birth (in months) in brackets. $* \mathrm{p}<0.1, * * \mathrm{p}<0.05, * * * \mathrm{p}<0.01$. 
Table 9: RD results by household characteristics - Men, 2005

(Estimates scaled up by 100)

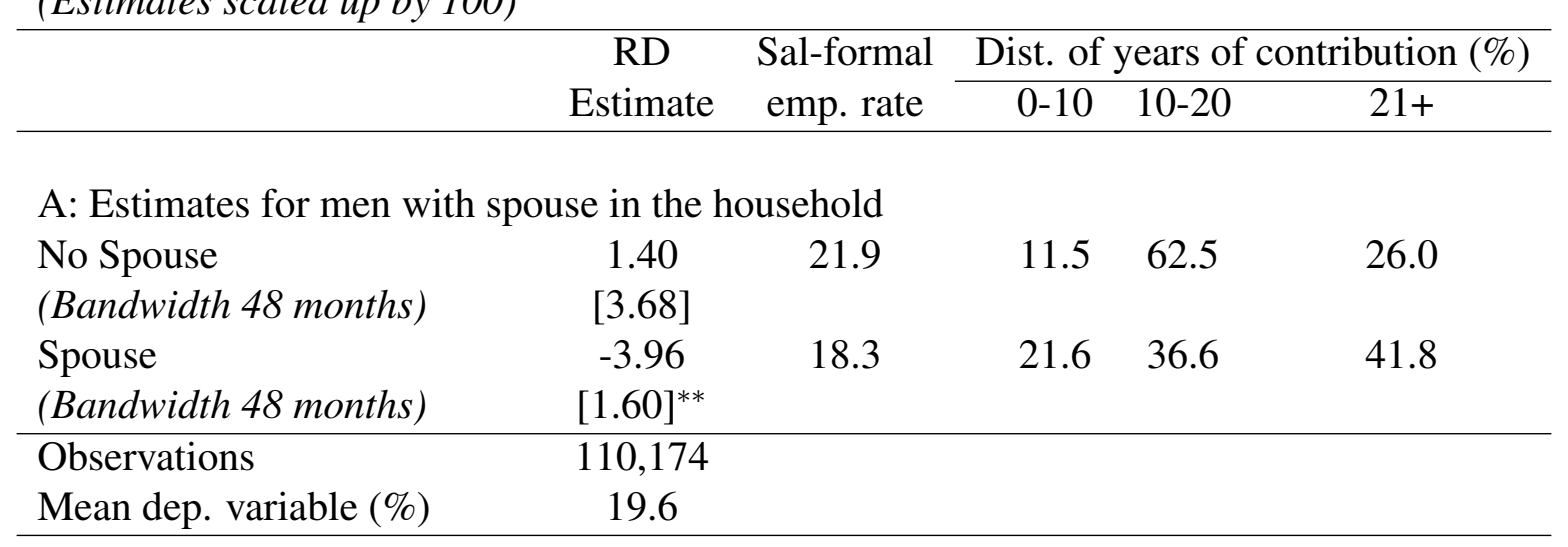

B: Estimates for men in households with one or more members in the labor force

\begin{tabular}{lccccc} 
More than one member in LF & -0.89 & 16.4 & 21.7 & 36.1 & 42.2 \\
(Bandwidth 48 months) & {$[1.83]$} & & & & \\
Only member in labor force & -6.23 & 20.3 & 15.9 & 50.7 & 33.4 \\
(Bandwidth 48 months) & {$[1.91]^{* * *}$} & & & & \\
\hline Observations & 110,174 & & & & \\
Mean dep. variable (\%) & 20.5 & & & & \\
\hline
\end{tabular}

Notes: The first column of the Table reports an RD estimate based on a separate regression of the salaried-formal employment indicator on a quadratic polynomial on date of birth and its interaction with a dummy for being born after March-54 (men) and March-59 (women) as independent variables (See equation (6)). The top panel reports the results for the samples of married and unmarried men, while the bottom panel reports the results for the sample of workers who are the only member of the family in the labor force. Regressions were estimated using the Colombian Census long-form questionnaire dataset. Standard errors clustered by date of birth (in months) in brackets. * $\mathrm{p}<0.1, * * \mathrm{p}<0.05, * * * \mathrm{p}<0.01$. The distribution of years of contribution is conditional on making contributions, and it is based on the Household Surveys data of 2006 and 2011. 
Table 10: Estimation results by region - Men, 2005 and 2011

\begin{tabular}{ccccc} 
(Estimates scaled up by 100) & & & \\
\hline RD & Sal-formal & Dist. of years of contribution (\%) \\
Estimate & emp. rate & $0-10$ & $10-20$ & $21+$
\end{tabular}

A: 2005 Results - Dependent variable: Salaried-formal employment indicator

\begin{tabular}{lccccc} 
Developing regions & -0.80 & 13.3 & 16.7 & 38.9 & 44.4 \\
(Bandwidth 48 months) & {$[1.66]$} & & & & \\
Developed regions & -3.99 & 21.3 & 22.4 & 40.3 & 37.3 \\
(Bandwidth 48 months) & {$[1.66]^{* *}$} & & & & \\
\hline Observations & 129,061 & & & & \\
Mean dep. variable (\%) & 18.1 & & & & \\
\hline
\end{tabular}

B: 2011 Results - Dependent variable: $\log$ number of workers

\begin{tabular}{lccccc} 
Developing regions & 1.58 & 18.1 & 14.0 & 38.4 & 47.7 \\
(Bandwidth 730 days) & {$[5.68]$} & & & & \\
Developed regions & 8.21 & 23.3 & 12.7 & 29.6 & 57.7 \\
(Bandwidth 730 days) & {$[2.38]^{* * *}$} & & & & \\
\hline Observations & 964,558 & & & & \\
\hline
\end{tabular}

Notes: The first column reports RD estimates based on a separate regression of a salaried-formal employment variable on a quadratic polynomial on date of birth and its interaction with a dummy for being born after March-54 (men) and March-59 (women) as independent variables by region (See equation (6)). The top panel presents results by region for 2005, while the bottom panel reports the results for 2011. I defined developed regions as the departments (provinces) with the highest GDP per capita excluding oil, namely, Bogota and Cundinamarca, Antioquia, and Valle, and less developed regions are the other provinces. Regressions were estimated using the Colombian Census long-form questionnaire (2005) and the PILA (2011) dataset. Standard errors clustered by date of birth (in months) in brackets. $* \mathrm{p}<0.1, * * \mathrm{p}<0.05, * * * \mathrm{p}<0.01$. The salaried-formal employment rate for 2011 is based on Household Surveys data. The distribution of years of contribution is conditional on making contributions, and it is based on the Household Surveys data of 2006 and 2011. 
Figure 1: Distribution of wages for workers with High School diploma or less, 2011

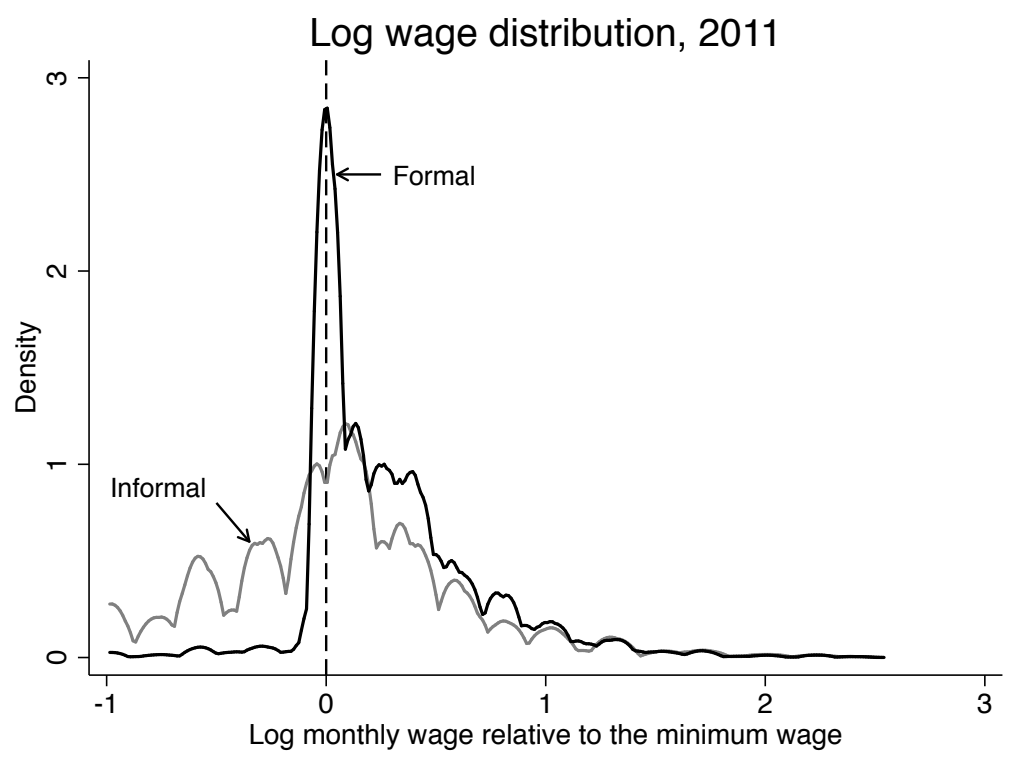

Notes: The figure displays kernel estimates of the density of the log monthly wage relative to the minimum wage for the formal (black line) and informal (grey line) sector. The selected sample includes all urban men and women aged 20 to 65, with High School diploma or less, working at least 30 hours per week. To minimize misreporting errors, I drop the top 1 percent wages and wages below 40 percent the minimum wage. Formal-sector workers are defined as workers who contributed to the pension and are covered by the contributory health care system.

Figure 2: Replacement rate for the defined-benefit systems by weeks of contributions

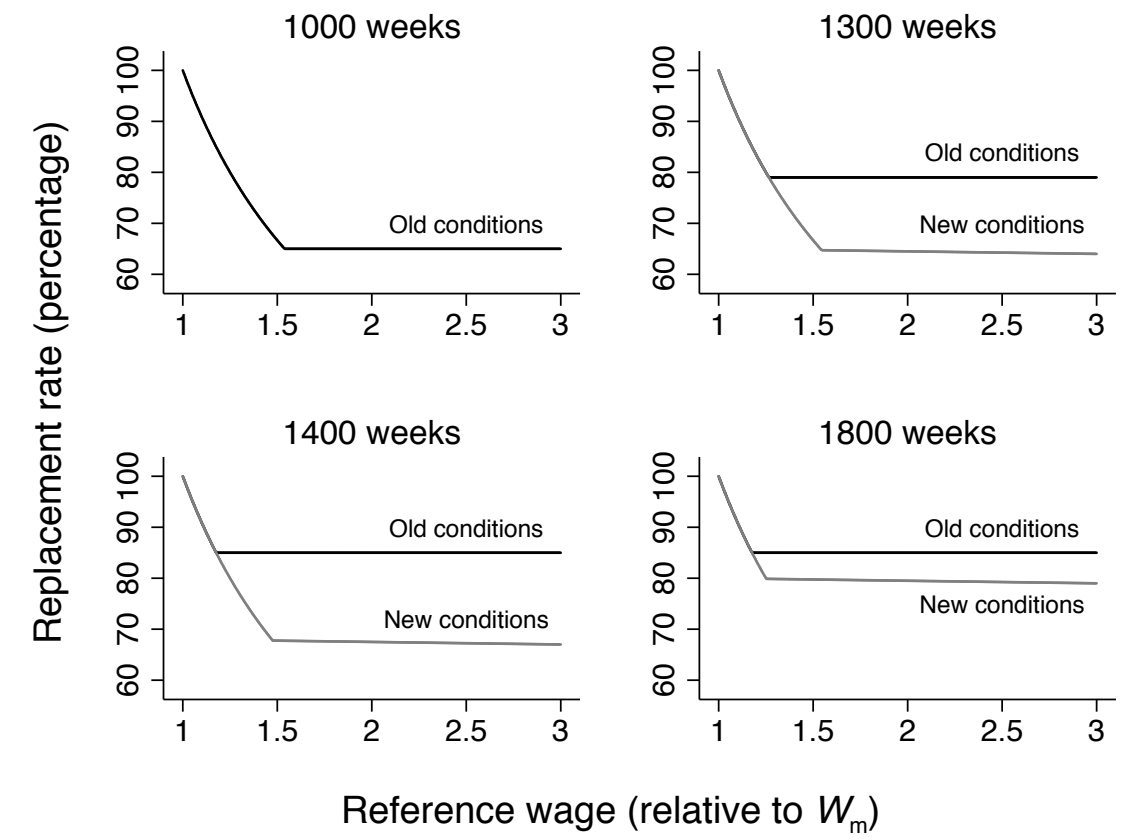

Notes: The figure displays the replacement rates as percentage of the reference wage for the social insurance (gray line) and the transition (black line) systems. Each panel represents the particular value of the formula defining the replacement rate by weeks of contributions. For the insurance system the vesting period is 1,300 weeks. 
Figure 3: Distribution of workers by age and number of weeks

Men
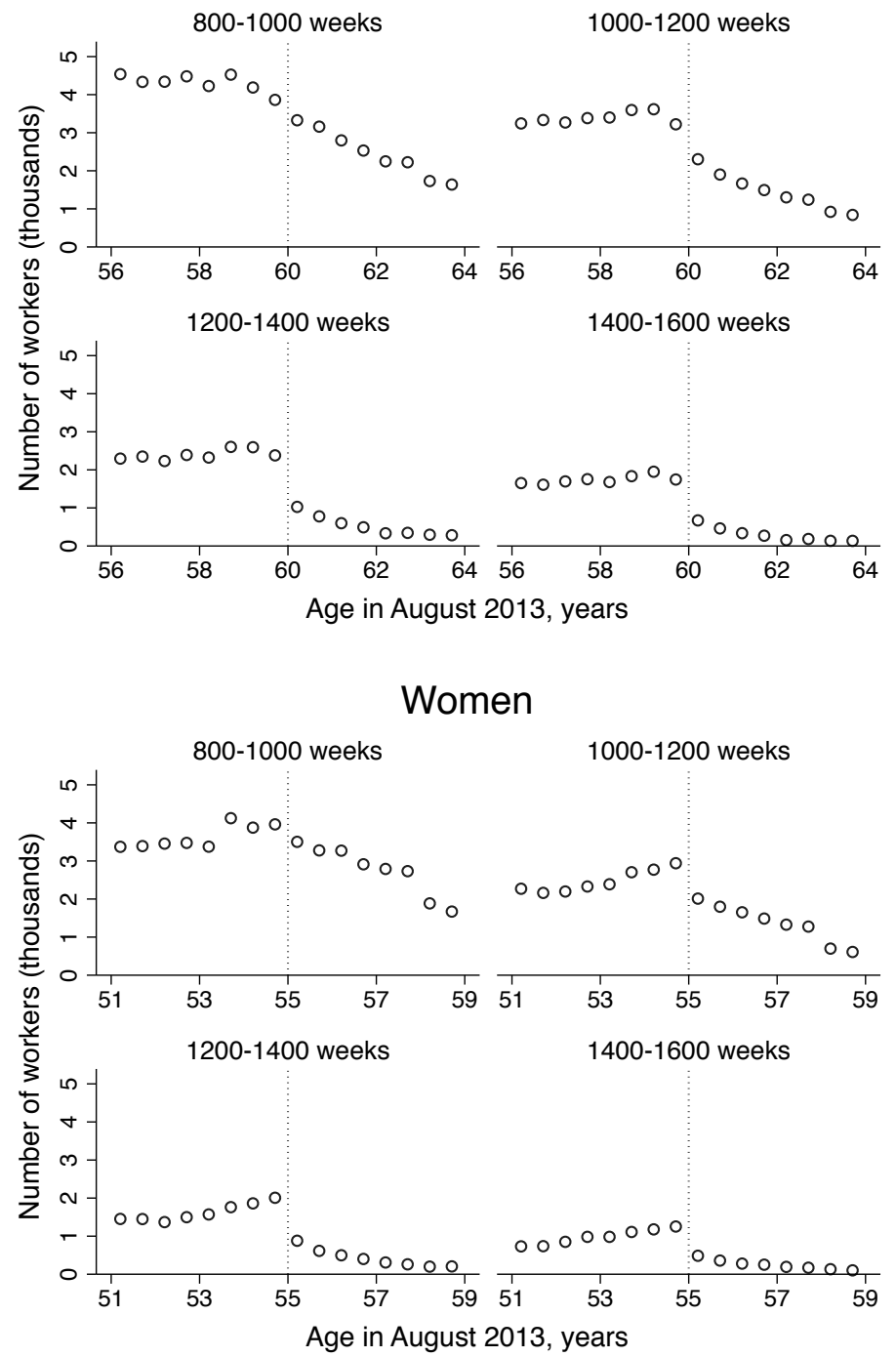

Notes: The figure presents the distribution by age, weeks of contribution and gender for non retired workers who have made contributions to the public pension system throughout their lifetime up to December 2013, based on Colpensiones administrative data. Once the workers claim the pension benefits they are excluded from the dataset. The reference date of birth is calculated relative to August 2013, as the expected processing time for awarding retirement benefits is four months. 
Figure 4: Probability of working in the formal-sector at age $a=50$

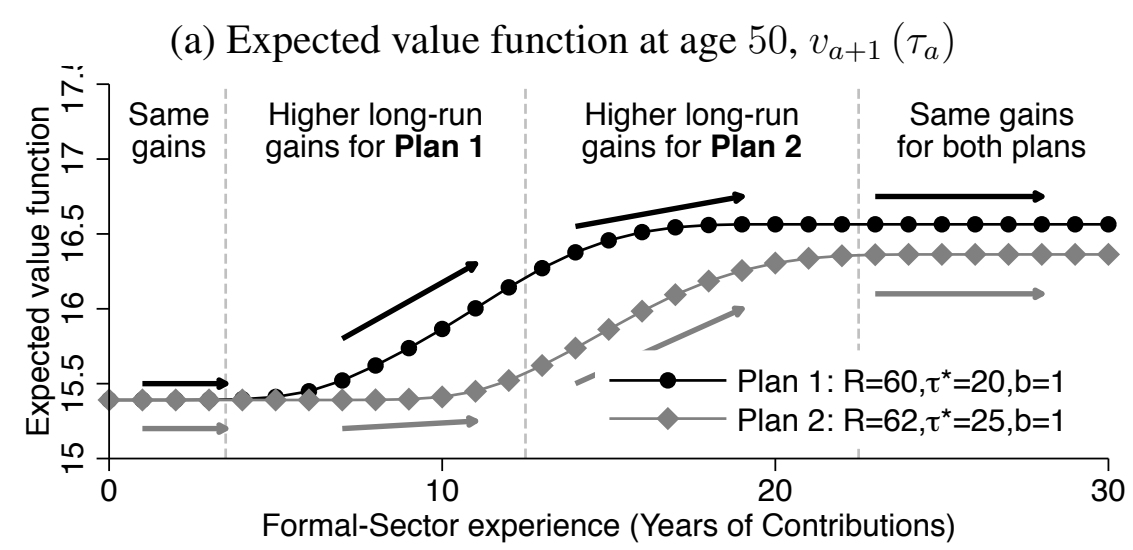

(b) Probability of working in the formal sector at age 50, $G\left(\bar{u}_{a}\left(\tau_{a-1}\right)\right)$

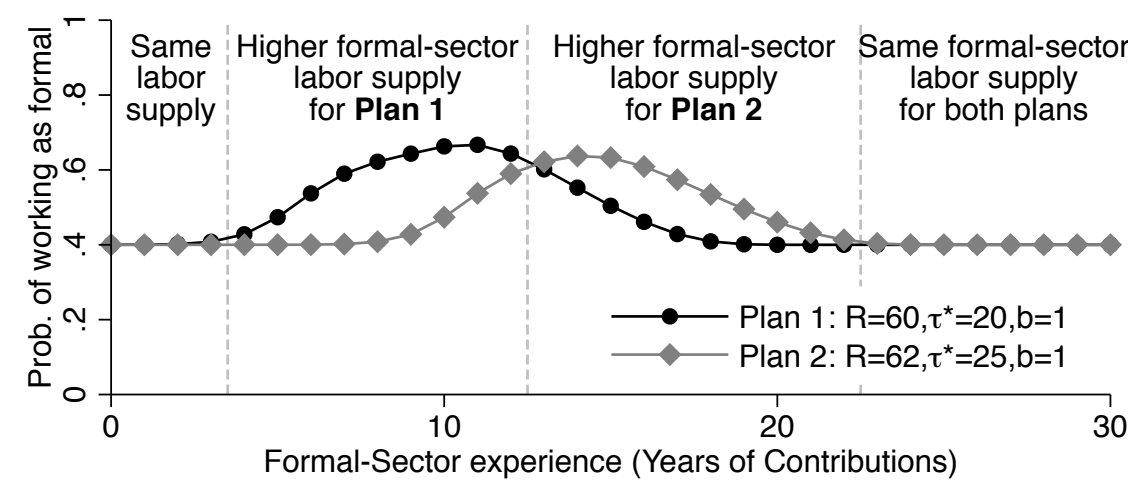

Notes: The figure shows an example of the expected value function $\left(v_{a+1}\left(\tau_{a}\right)\right.$, top) and the probability of searching for a formal-sector job $\left(G\left(\bar{u}_{a}\left(\tau_{a-1}\right)\right)\right.$, bottom) by years of contribution for two simulated cohorts aged $a=50$, given two defined-benefit pension plans. For the example, I assume that workers live from $a_{0}=20$ until $T=75$ and their utility function is linear. I also assume that $w^{f}\left(1-t^{n o m}\right)=1.2, w^{i}=1, \theta^{r}=\theta^{f}=0, \psi \stackrel{i . i . d}{\sim} \mathcal{U}(0,0.5)$, and $\beta=\frac{1}{1.05}$. The pension plans are given by $R=60, \tau^{*}=20$ and $b=1$ (labeled Plan 1 ) and $R=62, \tau^{*}=25$ and $b=1$ (Plan 2). Panel (a) shows the workers' expected value function by pension plan. Increasing the minimum qualifying conditions reduces the workers' expected utility and changes the long-run gains from working in the formal sector (the slope of the expected value function). Panel (b) shows the probability of working in the formal sector by pension plan. Harder qualifying conditions shift to the right the long-run gains from working one more period in the formal sector, as it takes longer to reach the vesting period. The response of formal-sector labor supply to harder qualifying conditions is heterogeneous, and depends on the workers' formal sector experience. 
Figure 5: Rolling t-statistics for testing the manipulation in date of birth, 2005

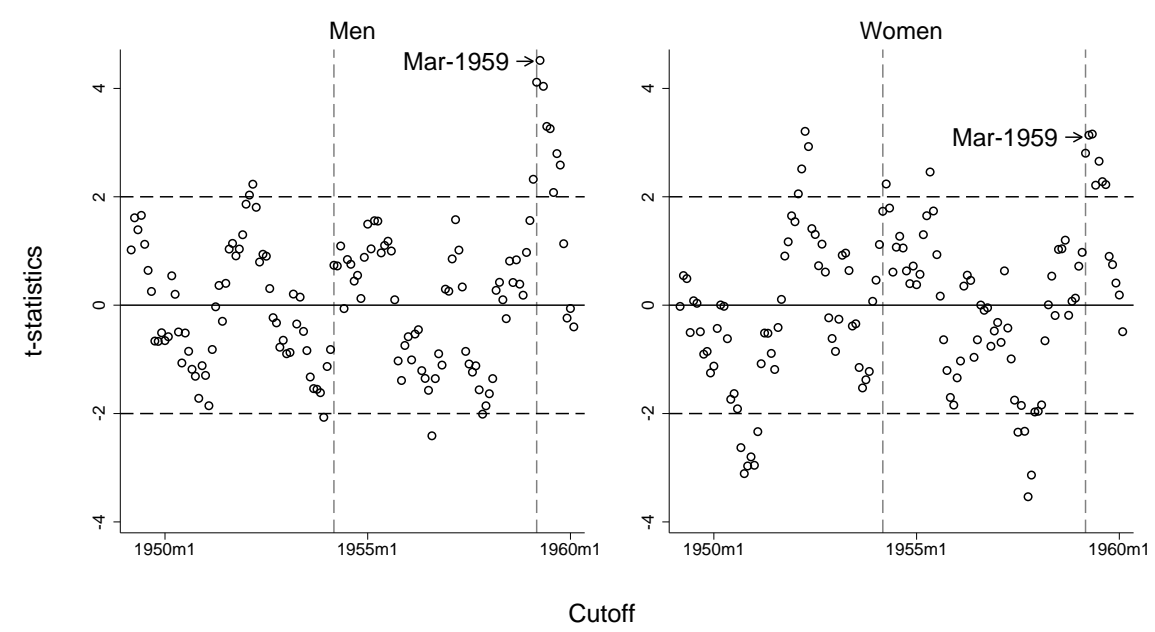

Notes: The figure displays the t-statistics using the test proposed by McCrary (2008) for testing discontinuities in the density of the running variable in the regression discontinuity setup. Each panel represents the value of the tstatistics changing the cutoff point, where the vertical dashed lines show the relevant cutoff dates for harder qualifying conditions in Colombia (April 1954 for men and April 1959 for women).

Figure 6: RD estimation results, 2005 and 2011
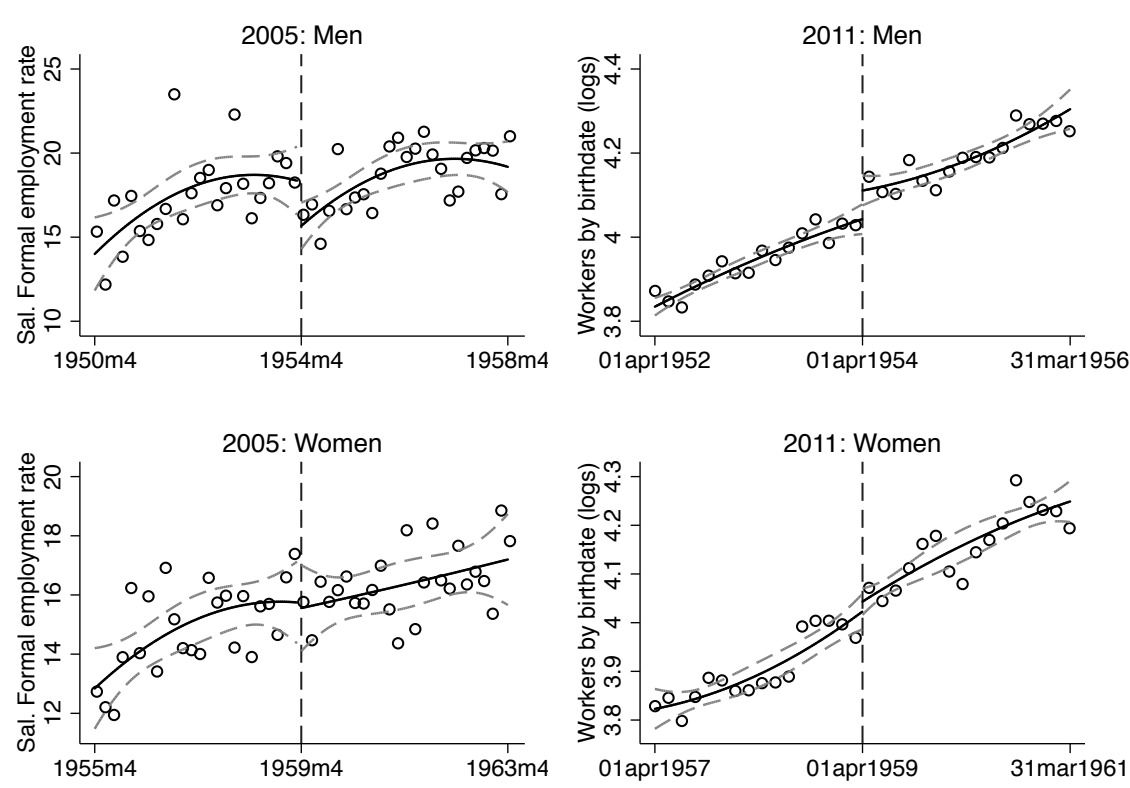

Date of Birth

Notes: The figure presents the salaried-formal employment indicators by gender and date of birth. Each point represents the 2-month average of the salaried-formal employment rate by month in 2005 and the 47-days average of the $\log$ number of workers by age in 2011. The regression estimates on the graphs are based on the estimates reported in panels $\mathrm{A}$ and $\mathrm{C}$ of Table 4. Confidence bands are computed based on standard errors clustered by date of birth (in months). 
Figure 7: Labor force participation, salaried-informal employment and self-employment rates for Men, 2005

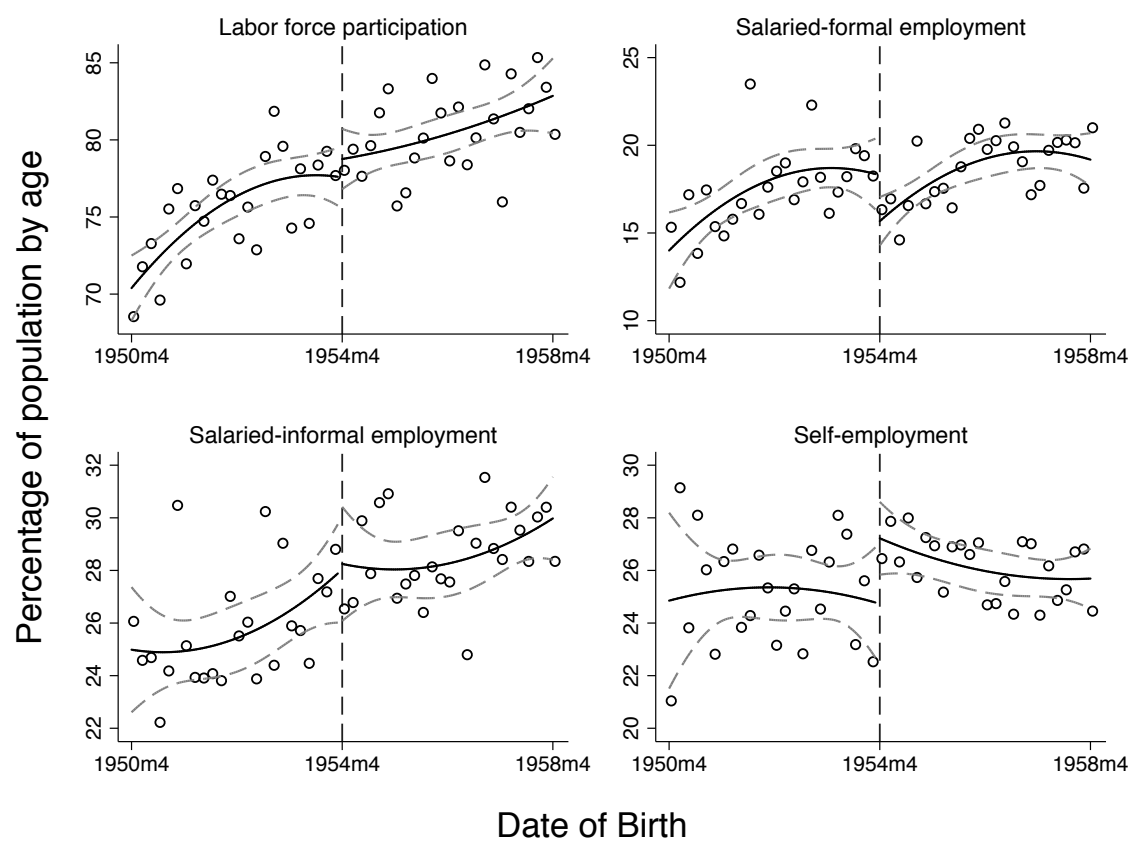

Notes: The figure presents the labor force participation rate, salaried-informal employment and self-employment rate for men by date of birth. Each point represents the 2-month average of the specific labor market outcome. The regression estimates on the graphs are based on the quadratic fit of the microdata (Table 6) of the Colombian Census long-form questionnaire dataset. Confidence bands are computed based on standard errors clustered by date of birth (in months). 
Figure 8: Elasticity of the formal-sector labor supply to changes in the net-of-tax share

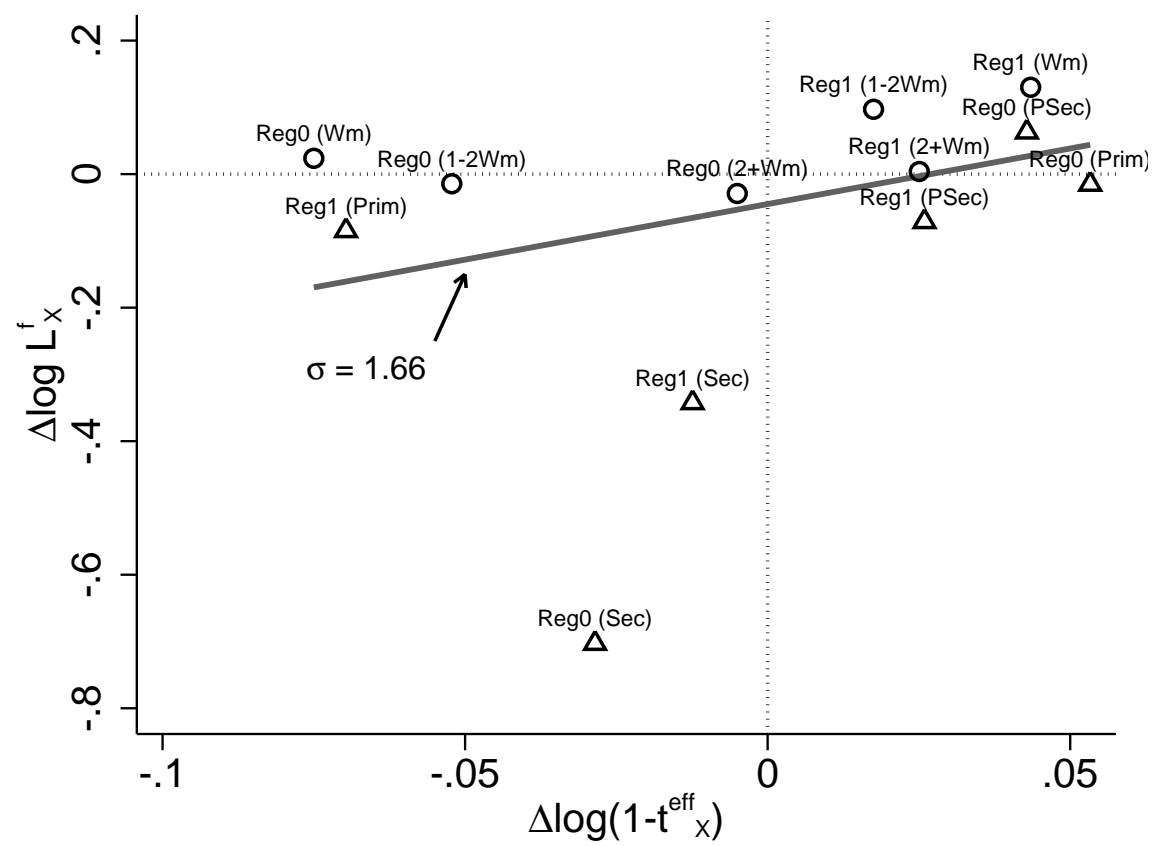

Notes: The Figure displays the average change in the log net-of-tax share (horizontal axis), computed in Section 5.3 , and the average change in the salaried-formal labor supply (vertical axis), derived from the results obtained in Section 5.2. Each point represents a combination of regions (developing and developed, denoted Reg0 and Reg1) and educational attainment (primary, secondary and post-secondary) or wage range (1, 1-2, 2+ Minimum wages). The regression slope corresponds to an estimate of the elasticity of the formal-sector labor supply with respect to the net-of-tax share along the formal-informal margin. 


\section{A Model implications and robustness tests}

The conditions characterizing the retirement and search decisions have useful implications to understand the empirical results of the paper. To simplify notation, let $u^{f}=u\left(w^{f}\left(1-t^{n o m}\right)\right)$ and $u^{i}=u\left(w^{i}\right)$ denote the utility levels the worker receives when working in the formal and informal sector, $u^{r}=u\left(b w^{f}\right)$ the utility the worker gets when he retires and is eligible for pension benefits, and $u^{0}=u(0)$ the baseline utility the worker receives when he retires but is not entitled to pension benefits. Thus, $\tilde{u}=u^{f}+\theta^{f}-u^{i}$ is the gap (in utility terms) between the formal an informal sector and $\bar{u}_{a}(\tau)=\tilde{u}+\beta \Delta v_{a+1}(\tau+1)$.

Most of the proofs use backward induction.

Proposition 1. A replacement rate of $b=1$ implies that the worker retires as soon as he meets the requirements.

Proof. Assume $b=1$ and $\tau^{*} \leq R<T$. In period $T$, the value function for retirement is given by

$$
v_{T}^{r}\left(\tau_{T-1}\right)=\left\{\begin{array}{ll}
u^{0} & \text { if } \tau_{T-1}<\tau^{*} \\
u^{r}+\theta^{r} & \text { if } \tau_{T-1} \geq \tau^{*}
\end{array} .\right.
$$

The value function if the worker continues working is

$$
v_{T}^{w}\left(\tau_{T-1}\right)=u^{i}+G(\tilde{u}) \mathbb{E}\left(\tilde{u}-\psi_{T} \mid \psi_{T} \leq \tilde{u}\right)
$$

By assumption $u^{0}<u^{i}$, and so the comparison of both value functions implies that the worker retires when $\tau_{T-1} \geq \tau^{*}$, and

$$
v_{T}\left(\tau_{T-1}\right)= \begin{cases}v_{T}^{w}\left(\tau_{T-1}\right) & \text { if } \tau_{T-1}<\tau^{*} \\ v_{T}^{r}\left(\tau_{T-1}\right) & \text { if } \tau_{T-1} \geq \tau^{*}\end{cases}
$$

For period $T-1$, the value function conditional on retirement and working are equal to

$$
\begin{aligned}
& v_{T-1}^{r}\left(\tau_{T-2}\right)= \begin{cases}u^{0}+\beta v_{T}^{r}\left(\tau_{T-2}\right) & \text { if } \tau_{T-2}<\tau^{*} \\
u^{r}+\theta^{r}+\beta v_{T}^{r}\left(\tau_{T-2}\right) & \text { if } \tau_{T-2} \geq \tau^{*}\end{cases} \\
& v_{T-1}^{w}\left(\tau_{T-2}\right)= u^{i}+\beta v_{T}\left(\tau_{T-2}\right)+ \\
& G\left(\bar{u}_{T-1}\left(\tau_{T-2}\right)\right) \times \\
& \mathbb{E}\left(\bar{u}_{T-1}\left(\tau_{T-2}\right)-\psi_{T-1} \mid \psi_{T-1} \leq \bar{u}_{T-1}\left(\tau_{T-2}\right)\right) .
\end{aligned}
$$


The second term of the latter equation is non negative, which implies that the worker does not retire when $\tau_{T-2}<\tau^{*}$. When $\tau_{T-2} \geq \tau^{*}$, rewrite $v_{T-1}^{w}\left(\tau_{T-2}\right)$ as

$$
\begin{aligned}
v_{T-1}^{w}\left(\tau_{T-2}\right)= & \left(1-G\left(\bar{u}_{T-1}\left(\tau_{T-2}\right)\right)\right)\left(u^{i}+\beta v_{T}\left(\tau_{T-2}\right)\right) \\
& +G\left(\bar{u}_{T-1}\left(\tau_{T-2}\right)\right)\left(u^{f}+\theta^{f}+\beta v_{T}\left(\tau_{T-2}+1\right)\right) \\
& -G\left(\bar{u}_{T-1}\left(\tau_{T-2}\right)\right) \mathbb{E}\left(\psi_{T-1} \mid \psi_{T-1} \leq \bar{u}_{T-1}\left(\tau_{T-2}\right)\right)
\end{aligned}
$$

which is strictly less than $v_{T-1}^{r}\left(\tau_{T-2}\right)$, and therefore the worker retires if $\tau_{T-2} \geq \tau^{*}$. A similar analysis applies for $a=R, R+1, \ldots, T-2$.

For $a \leq R-1$, the worker cannot claim pension benefits even if $\tau_{a-1} \geq \tau^{*}$. The value function if he retires is $v_{a}^{r}\left(\tau_{a-1}\right)=u^{0}+\beta v_{a}^{r}\left(\tau_{a-1}\right)$, which is less than $v_{a}^{w}\left(\tau_{a-1}\right)$. As a result, he does not retire before period $R$.

Proposition 2. The intensity of the search for formal-sector jobs depends on the likelihood of getting retirement benefits.

Proof. For simplicity, assume $b=1$ so the worker retires as soon as he mets the requirements. The proof of the proposition has two parts. First, I show that for workers for whom $\tau \geq \tau^{*}$ or $\tau+(T-a+1)<\tau^{*}, \Delta v_{a}(\tau+1)=0$ and therefore $\bar{u}_{a}(\tau)=\tilde{u}$. Second, I show that $\Delta v_{a}(\tau+1) \geq 0$ for all other values of $\tau$, and so $\bar{u}_{a}(\tau) \geq \tilde{u}$ for all $\tau$. As a result, workers who still have a chance of meeting the minimum requirement conditions are the ones who search more actively for formal-sector jobs.

First, there are two cases in which the accrual value of a period worked in the formal sector is zero: (i) when workers are vested $\left(\tau_{a-1} \geq \tau^{*}\right)$ and when workers do not have enough periods to reach $\tau^{*}\left(\tau_{a-1}+(T-a+1)<\tau^{*}\right)$.

For the first part of the proof, note that when $a \geq R$ and $\tau \geq \tau^{*}$, the optimal retirement decision implies that $v_{a}(\tau+1)=v_{a}(\tau)=v_{a}^{r}(\tau)$ for $a=R, \ldots T-1$. For the case $a=R-1$ and $\tau \geq \tau^{*}$, condition (2) implies that $u_{R-1}(\tau)=\tilde{u}$, and therefore the accrual value of an additional period worked in the formal sector is

$$
\Delta v_{R-1}(\tau+1)=(1-G(\tilde{u})) \beta \Delta v_{R}(\tau+1)+G(\tilde{u}) \beta \Delta v_{R}(\tau+2)=0 .
$$

The same argument can be extended for $a=\tau^{*}, \ldots, R-2$.

When $\tau_{T-1}+1<\tau^{*}, \Delta v_{T}\left(\tau_{T-1}+1\right)=0$ and $\bar{u}_{T-1}(\tau)=\tilde{u}$ for $\tau+1<\tau^{*}$. Using backward induction, the result follows.

Second, for $\tau \in\left[\tau^{*}-(T-a+1), \tau^{*}-1\right], \Delta v_{a}(\tau+1) \geq 0$. To see this, note first that from the definition of $v_{T}\left(\tau_{T-1}\right)$ presented above, $v_{T}(\tau+1) \geq v_{T}(\tau)$ for all $\tau$. For any other period 
$a<T$, assume $\bar{u}_{a}(\tau+1) \geq \bar{u}_{a}(\tau)$, and rewrite the first difference of the value function as

$$
\begin{aligned}
\Delta v_{a}(\tau+1)= & \left(1-G\left(\bar{u}_{a}(\tau)\right)\right) \beta \Delta v_{a+1}(\tau+1)+ \\
& G\left(\bar{u}_{a}(\tau+1)\right) \beta \Delta v_{a+1}(\tau+2)+ \\
& \left(G\left(\bar{u}_{a}(\tau+1)\right)-G\left(\bar{u}_{a}(\tau)\right)\right) \times \\
& \mathbb{E}\left(\tilde{u}-\psi_{a} \mid \bar{u}_{a}(\tau) \leq \psi_{a} \leq \bar{u}_{a}(\tau+1)\right) \\
\geq & \left(1-G\left(\bar{u}_{a}(\tau)\right)\right) \beta \Delta v_{a+1}(\tau+1)+G\left(\bar{u}_{a}(\tau)\right) \beta \Delta v_{a+1}(\tau+2) \\
\geq & 0
\end{aligned}
$$

and thus $\Delta v_{a}(\tau+1) \geq 0$. A similar argument can be used to show the result when $\bar{u}_{a}(\tau+1) \leq$ $\bar{u}_{a}(\tau)$.

Proposition 3. Assume $b=1$. Holding all other variables constant, a change in the minimum retirement age $R$ affects the incentives to search for formal-sector jobs. The effect is ambiguous and depends on a and $\tau_{a-1}$.

Proof. Assume an increase in the minimum age of retirement from $R$ to $R^{\prime}$. To characterize the full set of cases, assume that $R^{\prime}-R \geq 3$. Since $b$ equals one, workers retire as soon as they meet the requirements, and therefore a change in the minimum age of retirement affects the incentives to search for formal-sector jobs. ${ }^{17}$

Let $v_{a}(\tau)$ and $v_{a}^{\prime}(\tau)$ denote the value functions for the workers under $R$ and $R^{\prime}$. The effect of a change in the minimum retirement age depends on the worker's age $a$. For workers with $a \geq R^{\prime}$, there is no labor supply response, as a change in the retirement age does not change their retirement behavior. Therefore, $v_{a}(\tau)=v_{a}^{\prime}(\tau)$ for all $\tau$ and $a=R^{\prime}, \ldots, T$.

For $R \geq a>R^{\prime}$, the effect of changes in the retirement age the effect is ambiguous. To see this, start with $a=R^{\prime}-1$. Since $\Delta v_{R^{\prime}}(\tau+1)=\Delta v_{R^{\prime}}^{\prime}(\tau+1)$, the long-run gains from retirement do not change for this group, and so $\bar{u}_{R^{\prime}-1}(\tau)=\bar{u}_{R^{\prime}-1}^{\prime}(\tau)$. However, workers with $\tau \geq \tau^{*}$ are no longer eligible to retire, and so they search for formal-sector jobs. As a result, $v_{R^{\prime}-1}(\tau)=v_{R^{\prime}-1}^{\prime}(\tau)$ for $\tau<\tau^{*}$ and $v_{R^{\prime}-1}(\tau) \geq v_{R^{\prime}-1}^{\prime}(\tau)$ for $\tau \geq \tau^{*}$ (otherwise the retirement decision would not have been optimal). For this age group, there is an increase in formalsector employment, as the workers who are not longer eligible to retire search for formal-sector jobs - driven by short-run gains only. A direct implication of the definition of $v_{R^{\prime}-1}^{\prime}(\tau)$ is that $\Delta v_{R^{\prime}-1}(\tau+1)=\Delta v_{R^{\prime}-1}^{\prime}(\tau+1)$ for $\tau \neq \tau^{*}-1$ and $\Delta v_{R^{\prime}-1}\left(\tau^{*}\right) \geq \Delta v_{R^{\prime}-1}^{\prime}\left(\tau^{*}\right)$.

\footnotetext{
${ }^{17}$ The assumption $b=1$ is not a necessary condition for the proof. In order that a change in the minimum retirement age generates changes in the incentives to search for formal-sector jobs, it is necessary that at least a group of workers finds optimal to retire in an age $R^{*}$ such that $R \leq R^{*}<R^{\prime}$. Otherwise, the minimum retirement age is not binding and workers do not respond to the change.
} 
For $a=R^{\prime}-2$, the change in the incentives to search for formal-sector jobs depends on $\tau$. The definitions of $v_{R^{\prime}-1}(\tau)$ and $v_{R^{\prime}-1}^{\prime}(\tau)$ imply that $\bar{u}_{R^{\prime}-2}(\tau)=\bar{u}_{R^{\prime}-2}^{\prime}(\tau)$ for $\tau \neq \tau^{*}-1$ and $\bar{u}_{R^{\prime}-2}\left(\tau^{*}-1\right) \geq \bar{u}_{R^{\prime}-2}^{\prime}\left(\tau^{*}-1\right)$. Thus, the effect of a change in the minimum retirement age on the formal-sector labor supply response for is ambiguous, as there is a group that is not affected by the measure (those with $\tau \leq \tau^{*}-2$ ), a group that reduces its searching for formal-sector jobs ( $\tau=\tau^{*}-1$ ), and a group that increases their formal-labor supply, as they would have retired under the previous conditions $\left(\tau \geq \tau^{*}\right)$. Using the definition of $v_{a}(\tau), v_{R^{\prime}-2}(\tau)=v_{R^{\prime}-2}^{\prime}(\tau)$ for $\tau<\tau^{*}-1$ and $v_{R^{\prime}-2}(\tau)>v_{R^{\prime}-2}^{\prime}(\tau)$ for $\tau \geq \tau^{*}-1$.

Finally, $\Delta v_{R^{\prime}-2}(\tau+1)=\Delta v_{R^{\prime}-2}^{\prime}(\tau+1)$ for $\tau \notin\left\{\tau^{*}-2, \tau^{*}-1\right\}$ and $\Delta v_{R^{\prime}-2}(\tau+1) \geq$ $\Delta v_{R^{\prime}-2}^{\prime}(\tau+1)$ for $\tau \in\left\{\tau^{*}-2, \tau^{*}-1\right\}$ since

$$
\begin{aligned}
\overline{\Delta v_{R^{\prime}-2}\left(\tau^{*}-1\right)}= & \Delta v_{R^{\prime}-2}\left(\tau^{*}-1\right)-\Delta v_{R^{\prime}-2}^{\prime}\left(\tau^{*}-1\right) \\
= & \beta\left(v_{R^{\prime}-2}\left(\tau^{*}-1\right)-v_{R^{\prime}-2}\left(\tau^{*}-2\right)\right) \\
& -\beta\left(v_{R^{\prime}-2}^{\prime}\left(\tau^{*}-1\right)-v_{R^{\prime}-2}^{\prime}\left(\tau^{*}-2\right)\right) \\
= & \beta\left(v_{R^{\prime}-2}\left(\tau^{*}-1\right)-v_{R^{\prime}-2}^{\prime}\left(\tau^{*}-1\right)\right) \\
\geq & 0
\end{aligned}
$$

and

$$
\begin{aligned}
\overline{\Delta v_{R^{\prime}-2}\left(\tau^{*}\right)}= & \Delta v_{R^{\prime}-2}\left(\tau^{*}\right)-\Delta v_{R^{\prime}-2}^{\prime}\left(\tau^{*}\right) \\
= & \left(1-G\left(\bar{u}_{R^{\prime}-2}\left(\tau^{*}-1\right)\right)\right) \beta \Delta v_{R^{\prime}-1}\left(\tau^{*}\right) \\
& -\left(1-G\left(\bar{u}_{R^{\prime}-2}^{\prime}\left(\tau^{*}-1\right)\right)\right) \beta \Delta v_{R^{\prime}-1}^{\prime}\left(\tau^{*}\right) \\
& -\left(G\left(\bar{u}_{R^{\prime}-2}\left(\tau^{*}-1\right)\right)-G\left(\bar{u}_{R^{\prime}-2}^{\prime}\left(\tau^{*}-1\right)\right)\right) \times \\
& \mathbb{E}\left(\tilde{u}-\psi_{R^{\prime}-2} \mid \bar{u}_{R^{\prime}-2}^{\prime}\left(\tau^{*}-1\right) \leq \psi_{R^{\prime}-2} \leq \bar{u}_{R^{\prime}-2}\left(\tau^{*}-1\right)\right) \\
\geq & \left(1-G\left(\bar{u}_{R^{\prime}-2}\left(\tau^{*}-1\right)\right)\right) \beta\left(\Delta v_{R^{\prime}-1}\left(\tau^{*}\right)-\Delta v_{R^{\prime}-1}^{\prime}\left(\tau^{*}\right)\right) \\
\geq & 0 .
\end{aligned}
$$

For $a=R^{\prime}-3$, the change in the minimum retirement age have the same type of composition effects as those for $a=R^{\prime}-2$. In this case, the workers that exhibit a reduction in their formal-sector labor supply are those with $\tau \in\left\{\tau^{*}-3, \tau^{*}-2, \tau^{*}-1\right\}$. Again, $v_{R^{\prime}-3}(\tau)=$ $v_{R^{\prime}-3}^{\prime}(\tau)$ for $\tau<\tau^{*}-2$ and $v_{R^{\prime}-3}(\tau) \geq v_{R^{\prime}-3}^{\prime}(\tau)$ otherwise. Moreover, $\Delta v_{R^{\prime}-3}(\tau+1)=$ $\Delta v_{R^{\prime}-3}^{\prime}(\tau+1)$ for $\tau \notin\left\{\tau^{*}-3, \tau^{*}-2, \tau^{*}-1\right\}$ while $\Delta v_{R^{\prime}-3}(\tau+1) \geq \Delta v_{R^{\prime}-3}^{\prime}(\tau+1)$ for $\tau \in$ $\left\{\tau^{*}-3, \tau^{*}-2, \tau^{*}-1\right\}$. The proof of $\Delta v_{R^{\prime}-3}(\tau+1) \geq \Delta v_{R^{\prime}-3}^{\prime}(\tau+1)$ for $\tau \in\left\{\tau^{*}-3, \tau^{*}-1\right\}$ follows the same steps as those for $a=R^{\prime}-2$. For $\tau=\tau^{*}-2$, difference between the value 
functions is equal to

$$
\begin{aligned}
\overline{\Delta v_{R^{\prime}-3}\left(\tau^{*}-1\right)=} & \Delta v_{R^{\prime}-3}\left(\tau^{*}-1\right)-\Delta v_{R^{\prime}-3}^{\prime}\left(\tau^{*}-1\right) \\
= & \left(1-G\left(\bar{u}_{R^{\prime}-3}\left(\tau^{*}-2\right)\right)\right) \beta \Delta v_{R^{\prime}-2}\left(\tau^{*}-1\right) \\
& -\left(1-G\left(\bar{u}_{R^{\prime}-3}^{\prime}\left(\tau^{*}-2\right)\right)\right) \beta \Delta v_{R^{\prime}-2}^{\prime}\left(\tau^{*}-1\right) \\
& +G\left(\bar{u}_{R^{\prime}-3}\left(\tau^{*}-1\right)\right) \beta \Delta v_{R^{\prime}-2}\left(\tau^{*}\right) \\
& -G\left(\bar{u}_{R^{\prime}-3}^{\prime}\left(\tau^{*}-1\right)\right) \beta \Delta v_{R^{\prime}-2}^{\prime}\left(\tau^{*}\right) \\
& +\left(G\left(\bar{u}_{R^{\prime}-3}\left(\tau^{*}-1\right)\right)-G\left(\bar{u}_{R^{\prime}-3}^{\prime}\left(\tau^{*}-1\right)\right)\right) \times \\
& \mathbb{E}\left(\tilde{u}-\psi_{R^{\prime}-3} \mid \bar{u}_{R^{\prime}-3}^{\prime}\left(\tau^{*}-1\right) \leq \psi_{R^{\prime}-3} \leq \bar{u}_{R^{\prime}-3}\left(\tau^{*}-1\right)\right) \\
& -\left(G\left(\bar{u}_{R^{\prime}-3}\left(\tau^{*}-2\right)\right)-G\left(\bar{u}_{R^{\prime}-3}^{\prime}\left(\tau^{*}-2\right)\right)\right) \times \\
& \mathbb{E}\left(\tilde{u}-\psi_{R^{\prime}-3} \mid \bar{u}_{R^{\prime}-3}^{\prime}\left(\tau^{*}-2\right) \leq \psi_{R^{\prime}-3} \leq \bar{u}_{R^{\prime}-3}\left(\tau^{*}-2\right)\right) \\
\geq & \left(1-G\left(\bar{u}_{R^{\prime}-3}\left(\tau^{*}-2\right)\right)\right) \times \\
& \beta\left(\Delta v_{R^{\prime}-2}\left(\tau^{*}-1\right)-\Delta v_{R^{\prime}-2}^{\prime}\left(\tau^{*}-1\right)\right) \\
& +G\left(\bar{u}_{R^{\prime}-3}^{\prime}\left(\tau^{*}-1\right)\right) \beta\left(\Delta v_{R^{\prime}-2}\left(\tau^{*}\right)-\Delta v_{R^{\prime}-2}^{\prime}\left(\tau^{*}\right)\right) \\
\geq & 0 .
\end{aligned}
$$

Using backward induction, the implications above apply for all age groups $a=\left\{R, \ldots, R^{\prime}-3\right\}$.

For $a<R$, the effect of a change in the minimum age for retirement is a reduction of the formal-sector labor supply. In this case, the searching efforts of two types of workers are not affected by the change in $R$ : workers who are too far to retire before $R^{\prime}\left(\tau_{a-1}+R^{\prime}-a<\tau^{*}\right)$ and those who already met the vesting period $\left(\tau_{a-1} \geq \tau^{*}\right)$. For all other workers, the change in $R$ reduces their labor supply (the proof is similar to the presented above). Thus, for $a<R$, $v_{a+1}(\tau)=v_{a+1}^{\prime}(\tau)$ for $\tau<\tau^{*}+\left(R^{\prime}-a+1\right)$ and $v_{a+1}(\tau)>v_{a+1}^{\prime}(\tau)$ otherwise. In addition, $\Delta v_{a+1}(\tau+1) \geq \Delta v_{a+1}^{\prime}(\tau+1)$ for $\tau \in\left\{\tau^{*}-\left(R^{\prime}-a\right), \ldots, \tau^{*}-1\right\}$ and $\Delta v_{a+1}(\tau+1)=$ $\Delta v_{a+1}^{\prime}(\tau+1)$ otherwise.

Proposition 4. Assume $b=1$. Holding all other variables constant, a change in the vesting period $\tau^{*}$ affects the incentives to search for formal-sector jobs. The effect is ambiguous and depends on $a$ and $\tau_{a-1}$.

Proof. Given an increase of the vesting period from $\tau^{*}$ to $\tau^{\prime}$, the optimal retirement and searching policy change. Using the arguments presented in propositions 1 and 2, solving the model by backward induction yields a type of policy like the one presented before, but it uses $\tau^{\prime}$ as a reference point instead of $\tau^{*}$. Thus, the policy function shifts rightwards. The shift generates two types of changes within each cohort. Workers with $\tau_{a-1} \in\left\{\tau^{*}, \ldots, \tau^{\prime}\right\}$ increase their searching efforts, as 
they are not vested yet, and workers with low values of $\tau_{a-1}$ tend to reduce their efforts, as the probability of reaching the vesting period goes down. 
Table 11: Robustness test, 2005

\begin{tabular}{llllllll}
\hline & \multicolumn{3}{c}{ Men } & & \multicolumn{3}{c}{ Women } \\
\cline { 2 - 3 } \cline { 5 - 7 } \\
\hline
\end{tabular}

A: Least Squares estimator (estimates scaled up by 100)

$\begin{array}{lcccccc}\text { Linear control function } & -2.79 & -2.61 & -2.87 & -0.84 & -0.74 & -0.56 \\ \text { (Bandwidth 48 months) } & {[0.94]^{* * *}} & {[0.91]^{* * *}} & {[0.85]^{* * *}} & {[0.70]} & {[0.70]} & {[0.70]} \\ \text { Quadratic control function } & -2.62 & -2.36 & -2.52 & -0.18 & -0.13 & -0.15 \\ \text { (Bandwidth 48 months) } & {[1.28]^{* *}} & {[1.34]^{*}} & {[1.14]^{* *}} & {[1.03]} & {[1.00]} & {[1.05]}\end{array}$

B: Logit estimator (estimates scaled up by 100)

\begin{tabular}{|c|c|c|c|c|c|c|}
\hline Linear control function & -2.82 & -2.84 & -2.48 & -0.87 & -0.77 & -0.44 \\
\hline (Bandwidth 48 months) & {$[0.96]^{* * *}$} & {$[1.04]^{* * *}$} & {$[0.74]^{* * *}$} & [0.71] & {$[0.71]$} & {$[0.54]$} \\
\hline Quadratic control function & -2.48 & -2.39 & -2.00 & -0.15 & -0.10 & -0.10 \\
\hline (Bandwidth 48 months) & {$[1.27]^{*}$} & {$[1.42]^{*}$} & {$[0.95]^{* *}$} & [1.04] & {$[1.00]$} & {$[0.80]$} \\
\hline \multicolumn{7}{|c|}{ C: Local linear estimator (estimates scaled up by 100) } \\
\hline Local linear & -2.64 & - & - & -1.10 & - & - \\
\hline (Bandwidth 24 months) & {$[1.16]^{* *}$} & & & [0.94] & & \\
\hline Local linear & -2.80 & - & - & -0.68 & - & - \\
\hline (Bandwidth 36 months) & {$[1.03]^{* * *}$} & & & {$[0.83]$} & & \\
\hline Observations & 129,061 & 129,061 & 129,061 & 178,990 & 178,990 & 178,990 \\
\hline Mean dep. variable (\%) & 18.1 & 18.1 & 18.1 & 15.7 & 15.7 & 15.7 \\
\hline Fixed effects & & $\begin{array}{l}\text { Month of } \\
\text { birth }\end{array}$ & $\begin{array}{l}\text { High School } \\
\text { or less }\end{array}$ & & $\begin{array}{l}\text { Month of } \\
\text { birth }\end{array}$ & $\begin{array}{l}\text { High School } \\
\text { or less }\end{array}$ \\
\hline
\end{tabular}

Notes: Each cell reports an RD estimate based on a separate regression of an indicator variable of whether the person is a salaried worker contributing to the pension system and covered by the contributory health care system versus a polynomial on date of birth and its interaction with a dummy for being born after March-54 (men) and March-59 (women) as independent variables (See equation (6)). Columns (1) and (5) present the baseline regressions without any fixed effects, while the other columns include fixed effects to test the sensitivity of the results. The included fixed effects are based on categories of month of birth, educational attainment, and region. Regressions were computed using the Colombian Census long-form questionnaire dataset (2005). Standard errors clustered by date of birth (in months) in brackets. $* \mathrm{p}<0.1, * * \mathrm{p}<0.05, * * * \mathrm{p}<0.01$. 
Table 12: Robustness test, 2011

\begin{tabular}{|c|c|c|c|c|c|c|}
\hline & \multicolumn{3}{|c|}{ Men } & \multicolumn{3}{|c|}{ Women } \\
\hline & (1) & (2) & (3) & (4) & (5) & (6) \\
\hline
\end{tabular}

A: Least Squares estimator (estimates scaled up by 100)

$\begin{array}{lcccccc}\text { Linear control function } & 4.32 & 3.36 & 4.32 & 5.10 & 4.99 & 5.10 \\ \text { (Bandwidth 730 days) } & {[1.92]^{* *}} & {[1.43]^{* *}} & {[1.92]^{* *}} & {[1.98]^{* *}} & {[1.60]^{* *}} & {[1.98]^{* *}} \\ \text { Quadratic control function } & 6.79 & 5.84 & 6.79 & 2.03 & 1.89 & 2.03 \\ \text { (Bandwidth 730 days) } & {[2.39]^{* * *}} & {[2.04]^{* * *}} & {[2.39]^{* * *}} & {[2.17]} & {[1.58]} & {[2.17]}\end{array}$

B: Local linear estimator (estimates scaled up by 100)

\begin{tabular}{|c|c|c|c|c|c|c|}
\hline $\begin{array}{l}\text { Local linear } \\
\text { (Bandwidth } 360 \text { davs) }\end{array}$ & $\begin{array}{c}8.39 \\
{[2.24]^{* * *}}\end{array}$ & - & - & $\begin{array}{c}3.70 \\
{[1.63]^{* *}}\end{array}$ & - & - \\
\hline $\begin{array}{l}\text { Local linear } \\
\text { (Bandwidth } 540 \text { days) }\end{array}$ & $\begin{array}{c}6.74 \\
{[2.05]^{* * *}}\end{array}$ & - & - & $\begin{array}{c}3.85 \\
{[1.69]^{* *}}\end{array}$ & - & - \\
\hline Observations & 964,558 & 964,558 & 964,558 & 927,691 & 927,691 & 927,691 \\
\hline Fixed effects & & $\begin{array}{l}\text { Month of } \\
\text { birth }\end{array}$ & $\begin{array}{c}\text { Month of } \\
\text { contribution }\end{array}$ & & $\begin{array}{l}\text { Month of } \\
\text { birth }\end{array}$ & $\begin{array}{l}\text { Month of } \\
\text { contribution }\end{array}$ \\
\hline
\end{tabular}

Notes: Each cell reports an RD estimate based on a separate regression of the log number of salaried formal workers contributing to the pension system and the contributory health care system versus a polynomial on date of birth and its interaction with a dummy for being born after March-54 (men) and March-59 (women) as independent variables (See equation (6)). Columns (1) and (4) present the baseline regressions without any fixed effects, while the other columns include fixed effects to test the sensitivity of the results. The included fixed effects are based on categories of month of birth and month of contribution. Regressions were computed using the PILA dataset (2011). Standard errors clustered by date of birth (in months) in brackets. $* \mathrm{p}<0.1,{ }^{* *} \mathrm{p}<0.05,{ }^{* * *} \mathrm{p}<0.01$. 
Table 13: Estimation results with alternative definitions of formal employment,2005

\begin{tabular}{|c|c|c|c|c|c|c|c|c|}
\hline & \multicolumn{4}{|c|}{ Men } & \multicolumn{4}{|c|}{ Women } \\
\hline & $\begin{array}{c}\text { Salaried- } \\
\text { formal } \\
\text { (pension) } \\
(1)\end{array}$ & $\begin{array}{c}\text { Formal } \\
\text { worker } \\
(2)\end{array}$ & $\begin{array}{c}\text { Formal } \\
\text { worker } \\
\text { (Colp) } \\
(3)\end{array}$ & $\begin{array}{c}\text { Pension } \\
\text { (all) } \\
\\
(4)\end{array}$ & $\begin{array}{c}\text { Salaried- } \\
\text { formal } \\
\text { (pension) } \\
(5)\end{array}$ & $\begin{array}{c}\text { Formal } \\
\text { worker } \\
\text { (6) }\end{array}$ & $\begin{array}{c}\text { Formal } \\
\text { worker } \\
\text { (Colp) } \\
(7)\end{array}$ & $\begin{array}{l}\text { Pension } \\
\text { (all) } \\
\text { (8) }\end{array}$ \\
\hline \multicolumn{9}{|c|}{ Least Squares estimator (estimates scaled up by 100) } \\
\hline $\begin{array}{l}\text { Harder qualifying conditions } \\
\text { (Bandwidth } 48 \text { months) }\end{array}$ & $\begin{array}{c}-2.57 \\
{[1.42]^{*}}\end{array}$ & $\begin{array}{c}-2.71 \\
{[1.36]^{* *}}\end{array}$ & $\begin{array}{c}-2.17 \\
{[0.90]^{* *}}\end{array}$ & $\begin{array}{c}-3.49 \\
{[1.29]^{* * *}}\end{array}$ & $\begin{array}{l}-0.16 \\
{[1.08]}\end{array}$ & $\begin{array}{l}-0.36 \\
{[0.91]}\end{array}$ & $\begin{array}{c}0.02 \\
{[0.50]}\end{array}$ & $\begin{array}{l}-0.16 \\
{[1.02]}\end{array}$ \\
\hline Observations & 129,061 & 129,061 & 129,061 & 129,061 & 178,990 & 178,990 & 178,990 & 178,990 \\
\hline Mean dep. variable (\%) & 19.1 & 22.0 & 5.5 & 25.8 & 16.3 & 17.6 & 3.4 & 20.9 \\
\hline
\end{tabular}

Notes: Each cell reports an RD estimate based on a separate regression of formal employment versus a quadratic polynomial on date of birth and its interaction with a dummy for being born after March-54 (men) and March-59 (women) as independent variables (See equation (6)). The definitions used are (i) salaried-formal employment based on contributions to the pension system, regardless of coverage of the contributory health care system; (ii) formal employment for all workers contributing to the pension and covered by the contributory health care system, regardless of type of employment; (iii) formal employment for workers contributing to the pension system and covered by the contributory health care system managed by Colpensiones; and (iv) an indicator for all people contributing to the pension system, regardless of their labor force participation. Regressions were estimated using the Colombian Census long-form questionnaire dataset. Standard errors clustered by date of birth (in months) in brackets. ${ }^{*} \mathrm{p}<0.1, * * \mathrm{p}<0.05, * * * \mathrm{p}<0.01$. 